\title{
The U.S. Shale Oil Boom, the Oil Export Ban, and the Economy: A General Equilibrium Analysis
}

Nida Çakır Melek, Michael Plante and Mine Yücel

Federal Reserve Bank of Dallas Research Department Working Paper 1708 https://doi.org/10.24149/wp1708 


\title{
The U.S. shale oil boom, the oil export ban, and the economy: A general equilibrium analysis*
}

\author{
Nida Çakır Melek ${ }^{\dagger} \quad$ Michael Plante Mine K. Yücel $^{\ddagger}$
}

1st version: November 15, 2016

Current version: September 4, 2017

\begin{abstract}
This paper examines the effects of the U.S. shale oil boom in a two-country DSGE model where countries produce crude oil, refined oil products, and a non-oil good. The model incorporates different types of crude oil that are imperfect substitutes for each other as inputs into the refining sector. The model is calibrated to match oil market and macroeconomic data for the U.S. and the rest of the world (ROW). We investigate the implications of a significant increase in U.S. light crude oil production similar to the shale oil boom. Consistent with the data, our model predicts that light oil prices decline, U.S. imports of light oil fall dramatically, and light oil crowds out the use of medium crude by U.S. refiners. In addition, fuel prices fall and U.S. GDP rises. We then use our model to examine the potential implications of the former U.S. crude oil export ban. The model predicts that the ban was a binding constraint in 2013 through 2015. We find that the distortions introduced by the policy are greatest in the refining sector. Light oil prices become artificially low in the U.S., and U.S. refineries produce inefficiently high amount of refined products, but the impact on refined product prices and GDP are negligible.
\end{abstract}

Keywords: DSGE, oil, trade, fuel prices, export ban.

JEL Codes: F41, Q43, Q38.

*For helpful comments and suggestions we thank Nathan Balke, Michael Sposi, Kei-Mu Yi as well as participants of the USAEE 2015 and 2016 conferences, the 2015 NBER Meeting on Hydrocarbon Infrastructure, the 2015 Southern Economic Association Meeting, the 2016 IAEE conference, the 2016 Federal Reserve System Energy Meeting, the 2017 Georgetown Center for Economic Research Biennial Conference, the 2017 IAAE conference in Japan, the 2017 NBER Transporting Hydrocarbons and Economics of Energy Markets Meetings, and the seminar participants at the Federal Reserve Bank of Kansas City. This paper is part of the NBER Hydrocarbon Infrastructure Research Initiative supported by the Alfred P. Sloan Foundation. Navi Dhaliwal, Ruiyang Hu and Elena Ojeda provided excellent research assistance. This paper was previously circulated under the title "A macroeconomic analysis of lifting the U.S. crude oil export ban." The views expressed herein are solely those of the authors and do not necessarily reflect the views of the Federal Reserve Bank of Dallas, the Federal Reserve Bank of Kansas City or the Federal Reserve System.

${ }^{\dagger}$ Federal Reserve Bank of Kansas City, nida.cakirmelek@kc.frb.org.

${ }^{\ddagger}$ Federal Reserve Bank of Dallas, michael.plante@dal.frb.org.

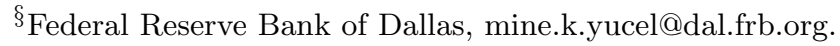




\section{Introduction}

The recent boom in U.S. crude oil production has been one of the most significant events in oil markets. Often referred to as the shale boom, the large increase in oil production brought about by the application of horizontal drilling and hydraulic fracturing has changed the nation's energy landscape and the dynamics of global oil markets. From 2010 to 2015, U.S. crude production increased from 5.5 million barrels per day $(\mathrm{mb} / \mathrm{d})$ to $9.6 \mathrm{mb} / \mathrm{d}$, and imports of crude oil fell almost $2 \mathrm{mb} / \mathrm{d}$.

An important facet of oil produced from shale is that it is predominantly light crude oil. The U.S. refining sector, on the other hand, has a comparative advantage in processing heavier crude oils relative to the rest of the world. The different oils are imperfect substitutes for each other as inputs into the refining sector. As a result, the large, unexpected increase in U.S. light oil production led to a mismatch of increased light crude inputs versus heavier refining capacity in the U.S. This issue was particularly relevant until the end of 2015, because the U.S. had an export ban on crude oil, a policy that had been put in place after the 1973 oil embargo.

The shale boom and the mismatch between increased production of light crude oil and the demand for that oil from U.S. refiners had some noticeable implications. For example, light oil imports into the U.S. declined dramatically, as some of the shale production was simply used to substitute for previously imported foreign light oil. Likewise, it was clear that the export ban constrained trade flows of crude oil and, at certain periods of time, depressed light oil prices in the U.S. ${ }^{1}$

What is less clear, though, is how and to what extent the shale boom and the export ban may have affected other oil market and macroeconomic variables. For instance, what quantitative impact did the light oil boom have on U.S. GDP? Did the export ban distort economic outcomes enough to affect the broader economy? How did the boom and the ban affect the refining sectors of the U.S. and the rest of the world? To address these questions, we develop a dynamic stochastic general equilibrium (DSGE) model and investigate the impact of the shale boom and the export ban on global oil markets, trade flows, the overall

\footnotetext{
${ }^{1}$ See, for example, Çakır Melek and Ojeda (2017) [18].
} 
U.S. economy, and the upstream and downstream energy industries. We show that the U.S. oil boom has sizable impacts not only on upstream and downstream energy sectors, but also on U.S. GDP and trade flows. The ban was a binding constraint with the distortions being greatest in the refining sector.

In our model, the world economy consists of two countries, the U.S. and the rest of the world (ROW). Both countries produce oil, a non-oil good and refined petroleum products (fuel). Oil itself is only used in the production of fuel, while fuel is used as a consumption good by households and as an intermediate input by firms that produce the non-oil good. The non-oil good is used for consumption and investment spending in both countries. To be able to study the effects of the shale boom and the export ban, we introduce a rich model of oil and refined products production. First, oil is not a homogenous commodity, a novel feature of the model. It comes in three types, light, medium and heavy. Second, different types of crude oil are imperfect substitutes as inputs into the refining process to produce fuel, another novel feature of the model. We calibrate our model to match a variety of macroeconomic and oil market data, and take into account important differences in the refining sectors of the U.S. and the rest of the world.

We model the U.S. shale oil boom as a series of positive productivity shocks that increase U.S. light crude oil production, and then illustrate the general equilibrium repercussions. We find that the light oil supply increase causes light oil prices to fall 20 percent and fuel prices to fall about 14 percent, boosting both household and firm fuel consumption. All imported light crude oil is backed out, leading to the U.S. becoming an exporter of light oil. U.S. imports of medium and heavy crudes also decline, as refiners substitute away from medium and heavy crudes. As a result, the U.S. oil trade balance improves significantly. Although the oil and gas sector is a small part of the U.S. economy, the boom in light oil supply increases U.S. GDP by more than 1.0 percent, a substantial impact, at one tenth of growth from 2010 to 2015 .

We then extend our baseline model to investigate the distortionary effects of the U.S. crude oil export ban, as the ban was in place during most of the shale boom. We find that the export ban was a binding constraint for several years, particularly in 2014 and 2015, and would have remained a binding constraint had the policy not been removed at the end 
of 2015. Our model shows that the export ban policy distorted the price of light crude oil in the U.S., making it artificially cheap relative to light oil in the ROW and relative to other grades of crude oil. This discount provided a cost advantage to the U.S. refining sector. As a result, the U.S. processed more light oil than it would otherwise, and gained market share at the expense of the rest of the world. The overall impact on the world fuel supply, however, was negligible, so was the impact on refined fuel prices, as there was no ban on refined petroleum products trade. Moreover, we see a very small improvement in the petroleum trade balance, due in part to increasing refined products exports. The impact on U.S. GDP was very slight, though, partly because of the upstream and downstream sectors being relatively minor components of U.S. GDP. Overall, our model does a good job in explaining the changes seen in the data, despite the fact that we rely only on a single shock.

Finally, we examine the data to see if there is evidence that the export ban may have been binding at some point in time. First, we do find evidence in line with model's predictions about the export ban. For example, the domestic price of light crude oil in the U.S. was unusually low compared to the international benchmark starting in late 2013. Data also show that U.S. crude oil exports continued increasing in 2016, despite lower production levels. Finally, we explore to what extent certain loopholes in the export ban policy were used to circumvent the ban. The data show that one such loophole, the ability to export to Canada, was used in 2014 and 2015 to a much larger extent than before. We conclude that the export ban was likely binding to some degree in 2014 and 2015.

Our model fits into the DSGE literature with oil, which includes works such as Backus and Crucini (2000) [3], who look at the impact of oil supply shocks on terms of trade, trade flows, and output, Bodenstein, Erceg and Guerrieri (2011) [11] who study the relationship between oil prices and the trade balance, Nakov and Nuno (2013) [37] who model the oil market as a dominant supplier and a competitive fringe, and Plante (2014) [38] who examines optimal monetary policy in the face of oil shocks. Our work also has connections with the international real business cycle literature, see for example Backus et al. (1992) [4], Backus et al. (1994) [5], Crucini and Kahn (1996) [17]. To the best of our knowledge, we contribute to this literature by being the first to introduce a distinction between different types of oil in a DSGE model, the first to model the refining sector and the first to explore the impact 
of the U.S. crude oil export ban in such a modeling framework.

There are several recent papers analyzing the U.S. shale oil boom and its effects on global oil prices, the global economy and the energy industry. Manescu and Nuno (2015) [33], using a general equilibrium model, show that the shale boom resulted in an increase of 0.2 percent of GDP for oil importers. Using a VAR model, Mohaddes and Raissi (2016) [36] show that the oil supply shock increased global GDP by 0.16 to 0.37 percentage points. Kang et. al. (2016) [27] find that a positive U.S. supply shock had a positive effect on U.S. stock returns using a structural VAR approach. ${ }^{2}$

Langer et al. (2016) [31] analyze the lifting of the export ban using a numerical, partial equilibrium model. ${ }^{3}$ They find that U.S. sweet crude exports expand significantly and the sweet oil-importing ROW gains from not having to invest in refinery capacity. Farrokhi (2016) [22] is the only study examining the oil export ban with a detailed refinery model in a multi-country general equilibrium model of oil trade. He examines the effects of counterfactual policies on oil prices and trade quantities across the world. He shows that if the crude oil export ban had been lifted during the shale boom, U.S. crude oil prices would have risen by 4.6 percent, U.S. refinery profits would have fallen by 6.3 percent, and refined product prices would have risen by 0.1 percent.

The rest of the paper is organized as follows. We present the background information and data in Section 2. Our general model framework is presented in Section 3. Section 4 provides the calibration, and results are discussed in Section 5. We introduce the crude oil

\footnotetext{
${ }^{2}$ Other studies include Walls and Zheng (2016) [44], Kilian (2016) [28] and Kilian (2017) [29], Bjornland et.al. (2016) [10], Arezki et.al. (2017) [2], Bornstein et.al. (2017) [13], and Mohaddes and Pesaran (2017) [35].

${ }^{3} \mathrm{~A}$ number of non-academic studies by national and international organizations discuss the impact of free trade policy relating to U.S. crude oil. These studies include Ebinger and Greenley (2014) [19], EIA (2014) [40], Vidas et.al. (2014) [43], IHS (2014) [25], IHS (2015) [26], which are typically qualitative in nature or rely on simple models in order to evaluate the impact. Overall, they argue that free trade would increase the price of domestic crude oil, hence could result in higher production and lower price of gasoline, benefiting consumers. The estimated decline in domestic gasoline prices change from 1.5 cents to 13 cents in these studies. A Congressional Research Service report by Brown et al. (2014) [15] has a good background analysis of the oil export ban and Bordoff and Houser (2015) [12] summarize several other reports on the issue, while Brown et al. (2014) [14] and Medlock (2015) [34] provide more academic analyses of the export ban.
} 
export ban and examine its implications in Section 6. Sensitivity analysis is undertaken in Section 7 and we conclude in Section 8.

\section{Data}

Our goal in this section is to review some key data to gauge how the shale boom has affected the oil market. To this end, we introduce data on crude oil production by type, U.S. imports and exports of crude oil and refined products, and refiner use of different types of oil. Using this data, we show the breakdown of production in the U.S. and the rest of the world, characterize the extent to which refiners in the U.S. are specialized in processing different types of oil and document how the data have changed since the onset of the shale boom.

\subsection{Introduction to crude oil quality}

Although crude oil is generally viewed as a homogenous commodity, crude oils vary across a number of dimensions. These include density, sulfur content, and contamination with other elements, such as certain metals.

The density of a crude oil is one of the more important measures used to distinguish between different types of oil. The American Petroleum Institute gravity (API gravity) is a commonly used measure of a crude oil's density with values ranging from 10 to 70 . A higher API gravity indicates less density. Oils with higher API gravities are known as light oils, those with low API gravities are known as heavy. Light oils tend to be preferred by refiners as they require less processing to produce larger amounts of gasoline and diesel. As a result, light oils often sell at a premium to medium and heavy crudes.

Sulfur content is another important characteristic that distinguishes crude oils. Oils with high sulfur content are referred to as sour while those with low sulfur content are sweet. The latter require less processing and are therefore preferred to sour oils. Generally speaking, there is a correlation between a crude's API gravity and the amount of sulfur present in the oil. Although not always the case, lighter oils often have lower sulfur content, especially when compared to heavy crudes.

Figure 2.1 shows how some important crude oil benchmarks vary in terms of their API 
Figure 2.1: Characteristics of various crude oils

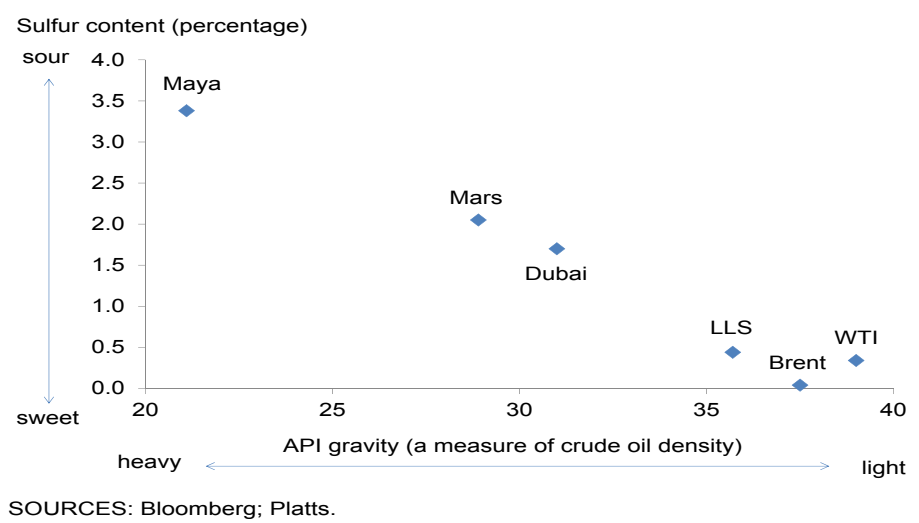

gravity and sulfur content. West Texas Intermediate, the benchmark crude oil for the U.S., is an important example of a light crude oil, with an API near 40 and a relatively low sulfur content. Other examples of light oils include Louisiana Light Sweet (LLS) and Brent which is an important benchmark outside the U.S. Maya crude, produced in Mexico, is an example of a heavy crude, a dense oil with a low API near 20 and a very high sulfur content relative to other crude oils. Mars is a medium crude produced in the U.S. Gulf of Mexico. It has an API and sulfur content in between the lights and Maya, and is similar in quality to Dubai, an important benchmark outside the U.S.

Prices of similar quality oils tend to remain fairly close to each other. ${ }^{4}$ As quality differences become more pronounced, so do the price differences between the oils. For example, if we consider the price of light, medium and heavy crude in the U.S. Gulf Coast, we see that the price of LLS has, on average, been about 12 percent higher than Mars crude oil since 1997, when data became available for Mars, and 27 percent more expensive than Maya.

Not surprisingly, the relative prices of different oils also tend to be more volatile as the quality differences become more pronounced. Using the Gulf Coast as an example again, we constructed a monthly time series from 1997 to 2010 for the price ratios of LLS to Brent, LLS to Mars and LLS to Maya. Figure 2.2 plots the coefficient of variation of these relative

\footnotetext{
${ }^{4}$ Factors such as transportation bottlenecks can occasionally cause prices of similar quality oils to deviate substantially from each other. An example of this in recent years is the price of WTI.
} 
oil prices as a function of how different each pair is in terms of API gravity. The more pronounced the quality differences become, the higher the coefficient of variation becomes. While this chart only considers three relative prices, a similar pattern emerges when looking at other crude oils. ${ }^{5}$

Figure 2.2: Coefficient of variation of relative oil prices

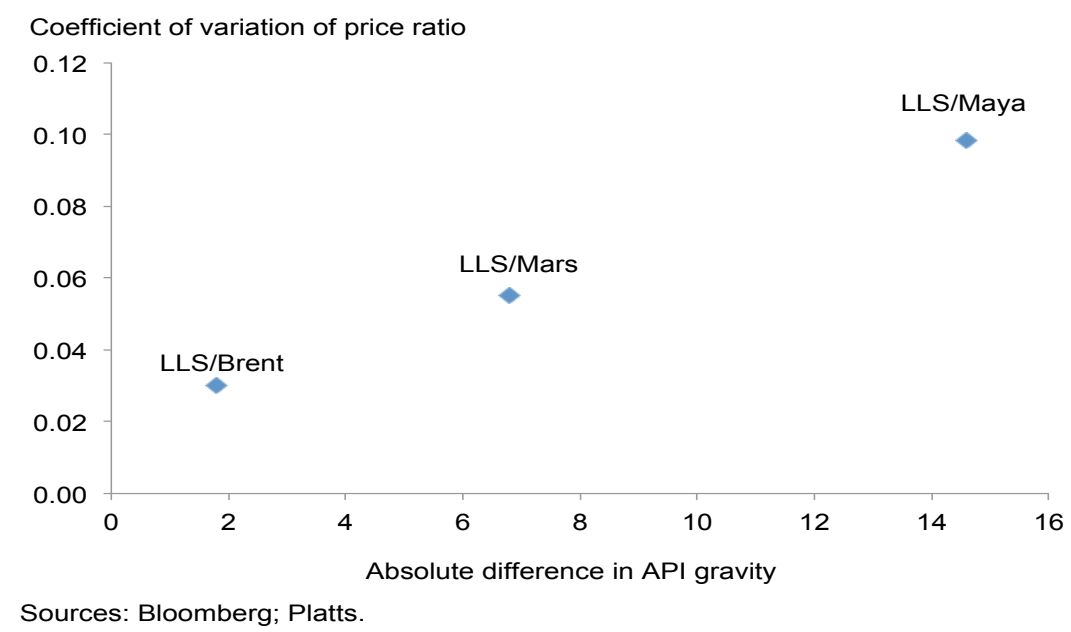

\subsection{Crude oil production}

We rely on production data from the 2017 version of Eni's World Oil and Gas Review [20]. It provides a breakdown of crude oil production into several different types. The breakdown covers world output and production in a number of countries, including the U.S. The data are available for a select number of years, including 2000, 2005 and from 2010 to 2016. Although this is a limited time series, it covers years when oil production in the U.S. boomed due to horizontal drilling and hydraulic fracking and does provide a snapshot of U.S. production before the boom.

Other sources of data on crude production by type are available but, unfortunately, they either have a limited time series or limited coverage. For example, the Energy Information Administration has recently started releasing monthly production data by API gravity for

\footnotetext{
${ }^{5}$ For example, a similar pattern is found if one uses the Asian benchmarks Tapis, Dubai and Duri crudes instead of LLS, Mars and Maya.
} 
the U.S. but the data only start in 2015. EIA (2015) [41] provides annual data but only for 2010 - 2013. We also constructed a longer time series for U.S. production using data from DrillingInfo and several other sources. However, this method produces a time series that often leaves a significant portion of production unclassified because of limited API gravity information. Neither source provides information for countries outside the U.S. As a result, we did not use these data for this paper.

We define different categories of crude oil using API gravity as our metric. We would have preferred to further expand the categorization to include sulfur content but could not because of data limitations. Following Eni, we define heavy crude oil as oil with an API less than 26, medium from 26 up to 35, and light crude oil with an API of 35 and above. Using these definitions, it is possible to construct a series for the U.S. and the rest of the world (ROW) for oil production by type. ${ }^{6}$

Table 2.1 shows the production data in millions of barrels per day $(\mathrm{mb} / \mathrm{d})$. One feature of the shale boom is that new production is primarily light oil. By 2015, light production had increased by $4.4 \mathrm{mb} / \mathrm{d}$ in the U.S., more than tripling its 2010 level. Outside the U.S., increased production was from medium and heavy crudes, with declines in light crude production.

\subsection{U.S. exports and imports: crude oil and refined products}

The EIA provides disaggregated data on U.S. crude imports by API gravity, which allows us to categorize imports into light, medium or heavy. Annual data go back until 1978. An extensive time series is available for annual crude exports but the EIA does not provide a breakdown by type. Given our interest in the shale boom, we focus on the more recent data available for both imports and exports.

The left portion of Table 2.2 shows the import data by type for 2000, 2005 and 2010 to 2016. We note that the U.S. has been and continues to be a major importer of crude oil. However, there have been some dramatic shifts in the quantity and types of oil being

\footnotetext{
${ }^{6} \mathrm{~A}$ small amount of world crude oil production, less than 1 percent of the total for most years, was unclassified by Eni. We distribute the unclassified amount equally between light, medium and heavy crude oil.
} 
Table 2.1: Crude oil production by type, $\mathrm{mb} / \mathrm{d}$

\begin{tabular}{cccc|ccc|ccc} 
& \multicolumn{3}{c}{ U.S. } & \multicolumn{3}{c}{ Rest of the world } & \multicolumn{3}{c}{ Total world } \\
\hline \hline 2000 & 2.1 & 2.9 & 0.8 & 20.1 & 34.9 & 7.6 & 22.2 & 37.8 & 8.4 \\
2005 & 1.7 & 2.8 & 0.7 & 19.9 & 40.3 & 9.5 & 21.6 & 43.0 & 10.1 \\
2010 & 2.1 & 2.8 & 0.6 & 20.8 & 38.8 & 9.9 & 23.0 & 41.6 & 10.4 \\
2011 & 2.6 & 2.5 & 0.6 & 19.7 & 40.2 & 10.0 & 22.3 & 42.7 & 10.5 \\
2012 & 3.5 & 2.4 & 0.6 & 20.1 & 41.0 & 9.8 & 23.6 & 43.4 & 10.4 \\
2013 & 4.5 & 2.4 & 0.6 & 19.6 & 40.5 & 10.1 & 24.2 & 42.9 & 10.7 \\
2014 & 5.9 & 2.4 & 0.6 & 19.0 & 41.4 & 10.2 & 24.8 & 43.8 & 10.9 \\
2015 & 6.5 & 2.5 & 0.6 & 19.1 & 42.0 & 11.1 & 25.6 & 44.5 & 11.7 \\
2016 & 5.9 & 2.5 & 0.6 & 19.3 & 42.6 & 10.9 & 25.2 & 45.1 & 11.4 \\
\hline
\end{tabular}

imported. Since the shale boom, imports of light oil have fallen substantially and imports of medium have declined. Imports of heavy crude have increased about 10 percent since 2010 and are up substantially since 2000. We note that imports of light oil picked up again in 2016, concurrent with the decline in U.S. light crude production that year.

The middle block of Table 2.2 shows the data for U.S. crude exports. From 2000 to 2013, the U.S. exported a trivial amount of crude oil, typically under $100 \mathrm{~kb} / \mathrm{d}$. Exports picked up noticeably starting in 2014, however, and have continued increasing every year since. The increase in exports in 2014 and 2015 might seem at odds with the U.S. policy of prohibiting exports of crude oil that was in place at the time. A short discussion on the policy will help provide some context for this.

Until December 2015, there was a federal ban on crude oil exports whose motivation dated back to the 1973 oil embargo. Although labeled a ban, exporting oil was possible under certain circumstances. The most relevant exemption for recent export data was the possibility to export crude oil to Canada. ${ }^{7}$ This could be done so long as the oil was not

\footnotetext{
${ }^{7}$ Another exemption regarded exports of Alaskan crude oil. However, exports from Alaska have been negligible since 2000. More details can be found in Bausell et al. (2001) [8], Kumins (2005) [30] and Van Vactor (1995) [42].
} 
Table 2.2: U.S. crude oil and refined products exports and imports, mb/d

\section{U.S. crude imports U.S. crude exports U.S. refined products}

\begin{tabular}{cccc|c|c} 
& Light & Medium & Heavy & Total & Net imports \\
\hline \hline 2000 & 2.2 & 4.6 & 2.3 & 0.05 & 0.87 \\
2005 & 2.3 & 4.3 & 3.5 & 0.03 & 2.00 \\
2010 & 2.1 & 3.3 & 3.8 & 0.04 & 0.08 \\
2011 & 1.7 & 3.3 & 4.0 & 0.05 & -0.35 \\
2012 & 1.4 & 3.1 & 4.0 & 0.07 & -1.00 \\
2013 & 0.9 & 3.0 & 3.9 & 0.13 & -1.13 \\
2014 & 0.6 & 2.7 & 4.1 & 0.35 & -1.49 \\
2015 & 0.6 & 2.6 & 4.2 & 0.47 & -1.51 \\
2016 & 0.9 & 2.6 & 4.4 & 0.52 & -1.48 \\
\hline
\end{tabular}

re-exported from Canada. This exemption was used heavily in both 2014 and 2015, with the EIA export data showing that most U.S. exports of crude oil went to Canada which can be seen in figure 2.3 .

Figure 2.3: U.S. crude oil exports

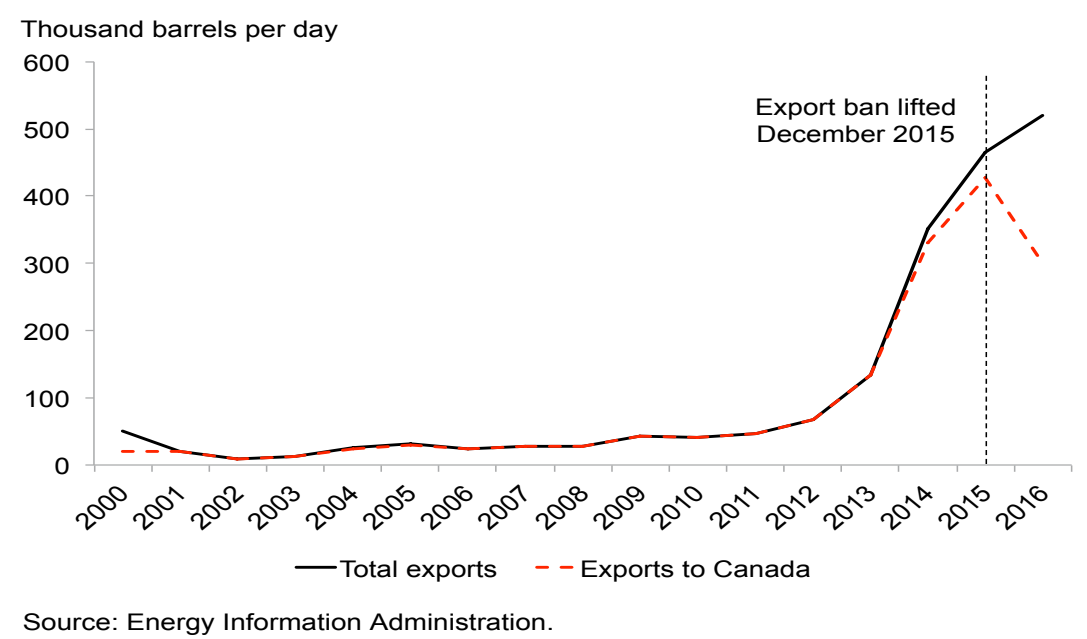

The rightmost column of Table 2.2 shows net imports of U.S. refined products. Over the course of the shale boom there was a significant increase in the production of refined 
products. As the export ban did not apply to refined petroleum products, exports of products increased significantly and by 2011 the United States had become a net exporter.

\subsection{Refiner inputs by type of oil}

We next construct an estimate of how much oil of each type is being processed by refiners in the U.S. and ROW. Our estimate of U.S. refiner inputs by type is given by the following,

$$
\operatorname{Input}_{t}^{j}=\operatorname{Production}_{t}^{j}+\operatorname{Imports}_{t}^{j}-\text { Exports }_{t}^{j},
$$

where each variable is for the U.S. and the types are indexed by $j=l, m, h$. The production data comes from Eni, while the import and export data are from the EIA.

As mentioned previously, the EIA does not provide a breakdown of the export data by type of oil. For most of the years considered, exports were relatively small and could be ignored without significantly affecting our estimates. This is not true for 2014 and 2015, however. Data available from Canada, along with analysis from several other sources, suggest that most, if not all, of the oil exported to Canada was of the light variety. ${ }^{8}$ Given this, we assume that all U.S. exports of crude oil from 2010 to 2016 were light. This has the effect of lowering our estimate for U.S. refiner use of light crude oil, particularly from 2014 to 2016.

The estimate for ROW is then constructed by calculating the difference between world oil production of type $j$ and U.S. refiner use of type $j$. We note that it would be preferable to account for crude oil inventory changes when making this calculation. However, we are unaware of any data that would allow us to break inventory changes into the respective types, even in the U.S. Outside of the U.S, data are also limited regarding overall crude oil inventory changes. We do note, however, that changes in crude oil inventories in the U.S. from year to year, at least, tend to be very small when compared to the other flow data we are interested in. For example, crude inventories changed by $+.02 \mathrm{mb} / \mathrm{d},-.01 \mathrm{mb} / \mathrm{d}$ and + $.1 \mathrm{mb} / \mathrm{d}$ in 2010, 2011 and 2012, respectively. These are fairly small compared to the amount of oil being processed by U.S. refiners each day.

Table 2.3 shows our estimates for refining inputs. As can be seen in the table, the U.S. refinery sector is geared towards processing heavy crude oil relative to the rest of the world.

\footnotetext{
${ }^{8}$ See Çakır Melek and Ojeda (2017) [18] for more details.
} 
Table 2.3: Refiner inputs by type, U.S. and rest of the world, mb/d

\begin{tabular}{cccc|ccc} 
& \multicolumn{3}{c}{ U.S. refiner inputs } & \multicolumn{2}{c}{ ROW } & refiner inputs \\
& Light & Medium & Heavy & Light & Medium & Heavy \\
\hline \hline 2000 & 4.3 & 7.5 & 3.1 & 17.9 & 30.4 & 5.4 \\
2005 & 4.1 & 7.0 & 4.2 & 17.6 & 36.0 & 6.0 \\
2010 & 4.2 & 6.1 & 4.4 & 18.8 & 35.5 & 6.1 \\
2011 & 4.2 & 5.8 & 4.5 & 18.1 & 37.0 & 6.0 \\
2012 & 4.9 & 5.6 & 4.5 & 18.7 & 37.9 & 5.9 \\
2013 & 5.3 & 5.3 & 4.5 & 18.9 & 37.5 & 6.2 \\
2014 & 6.1 & 5.1 & 4.7 & 18.7 & 38.7 & 6.2 \\
2015 & 6.6 & 5.1 & 4.8 & 19.0 & 39.4 & 6.9 \\
2016 & 6.3 & 5.1 & 5.0 & 19.0 & 40.0 & 6.4 \\
\hline
\end{tabular}

This can also be seen in Figure 2.4, where we plot 2010 data for illustrative purposes. In that year, the U.S. alone processed more than 40 percent of the world's heavy crude oil. On the other hand, the U.S. processed about 18 percent of the world's light crude, and only around 15 percent of the world's medium crude. The over-weighting of the U.S. refining sector in terms of how much heavy crude oil it processes reflects the fact that the U.S. has a number of very large, complex refineries that are able to efficiently process heavy crude oils.

\subsection{Summary: changes since 2010}

There have been some dramatic changes not only in U.S. oil production but also in crude imports, exports and refining data since the start of the shale boom. We take stock of these in Table 2.4 by comparing how select data for the U.S. has changed from 2010 to 2015.

The impact of the new technology on production is immediately obvious. Light production increased by $4.4 \mathrm{mb} / \mathrm{d}$ over the 5 year period. Production of other types was relatively flat, with production of medium crudes down slightly and heavy crude production essentially unchanged. 
Figure 2.4: Global refining shares by type of oil, U.S. and the ROW, 2010

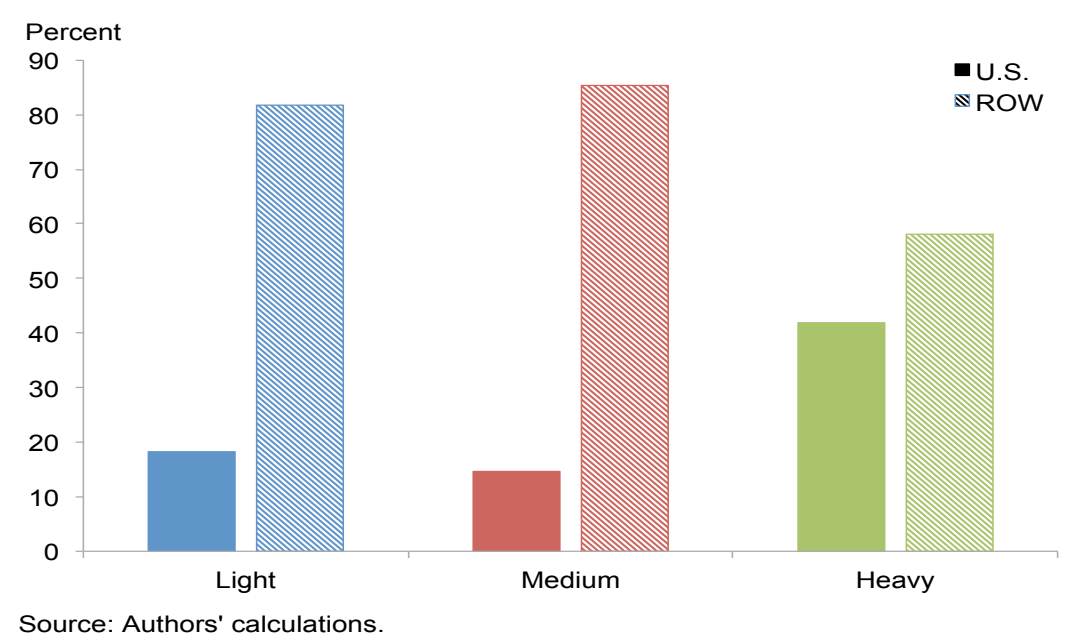

Refiner use of light oil also increased substantially, with U.S. refiners processing an additional $2.4 \mathrm{mb} / \mathrm{d}$ in 2015 vs. 2010. The increase was insufficient to absorb all new U.S. light production. As a result, imports of light oil from other countries dropped sharply. There was also an increase in exports, primarily to Canada, especially in 2015.

One feature of the data that does not receive much attention concerns imports and refiners' use of medium crude oil. U.S. refiners reduced their use of medium crudes by 1 $\mathrm{mb} / \mathrm{d}$, leading to a significant drop in imports. One possibility is that light oil may have crowded out medium oil. We will return to this point later when discussing results from our theoretical model.

Finally, U.S. refiners have continued increasing their usage of heavy crude oil over these years. Based on the Eni data, world production of heavy crude was about $1.3 \mathrm{mb} / \mathrm{d}$ higher in 2015 than in 2010. U.S. refiners processed about 40 percent of the increase, with the crude being imported from other countries.

Motivated by these facts, the next section presents our theoretical framework used to evaluate the impact of U.S. shale oil boom on upstream and downstream energy sectors, trade flows, and the overall U.S. economy. 
Table 2.4: Change in select U.S. data from 2010 to $2015, \mathrm{mb} / \mathrm{d}$

\begin{tabular}{lcccc} 
& Production & Imports & Exports & Refiner inputs \\
\hline \hline Light & 4.4 & -1.5 & 0.4 & 2.4 \\
\multirow{2}{*}{ Medium } & $(204)$ & $(-73)$ & $(1017)$ & $(57)$ \\
& -0.3 & -0.8 & & -1.0 \\
\multirow{2}{*}{ Heavy } & $(-9)$ & $(-23)$ & & $(-17)$ \\
& 0.02 & 0.4 & & 0.5 \\
Total & $(3)$ & $(12)$ & & $(11)$ \\
& 4.1 & -1.9 & 0.4 & 1.8 \\
& $(75)$ & $(-20)$ & $(1017)$ & $(13)$ \\
\hline
\end{tabular}

Note: \% changes from 2010 to 2015 are presented in parentheses.

\section{Baseline Model}

The world economy is represented by a dynamic stochastic general equilibrium model that consists of two countries, the U.S. and the rest of the world (ROW). ${ }^{9}$ We refer to the U.S. as country 1 and ROW as country 2. Both countries produce three goods: crude oil, refined oil products, and a non-oil good. Their preferences and technologies have the same functional forms. Crude oil is produced using the non-oil good as an input and comes in three types: light, medium or heavy crude. Production of refined products requires capital, labor, and a composite of the three types of crude oil. The household consumption bundle is a composite of refined products and the non-oil good. Finally, the non-oil good is produced using capital, labor, and refined products. We abstract from internationally traded financial assets in the model so trade balances each period in the model.

\footnotetext{
${ }^{9}$ See Backus and Crucini (2000) [3], Backus et al. (1992) [4], Backus et al. (1994) [5], Crucini and Kahn (1996) [17], etc. for more details on this framework.
} 


\subsection{Households}

The utility of a typical household in country $i, i=1,2$, is characterized by

$$
E_{0} \sum_{t=0}^{\infty} \beta^{t} \frac{\left(c_{i, t}^{\mu_{i}} L_{i, t}^{1-\mu_{i}}\right)^{\gamma}}{\gamma}
$$

where $c_{i, t}$ and $L_{i, t}$ are aggregate consumption and leisure, respectively. The parameter $0<\beta<1$ denotes the discount factor, $\mu_{i}$ governs the time spent in the workplace, and $\gamma$ governs the intertemporal elasticity of substitution. We assume that crude oil is not directly consumed by households, but is used only in the production of refined products (fuel). The variable $c$ measures aggregate consumption and is a composite of the non-oil good, good $a$, and refined products, good $f$, which are combined via an Armington aggregator with weights $w_{i}$ and $\left(1-w_{i}\right)$ as follows

$$
c_{i, t}=\left[w_{i}\left(c_{i, t}^{a}\right)^{-\rho}+\left(1-w_{i}\right)\left(c_{i, t}^{f}\right)^{-\rho}\right]^{\frac{-1}{\rho}},
$$

where $\frac{1}{1+\rho}$ is the elasticity of substitution between $c_{i, t}^{a}$ and $c_{i, t}^{f}$. The aggregator function captures the idea that these goods are imperfect substitutes, and the weights reflect how consumption expenditures are allocated across these goods.

The household faces a budget constraint in period $t$ stating that the combined expenditure on consumption and investment must equal income:

$$
c_{i, t}^{a}+p_{i, t}^{f} c_{i, t}^{f}+I_{i, t}^{a}+I_{i, t}^{f}=W_{i, t}^{a} n_{i, t}^{a}+W_{i, t}^{f} n_{i, t}^{f}+R_{i, t}^{a} K_{i, t}^{a}+R_{i, t}^{f} K_{i, t}^{f}+\Pi_{i, t}^{a}+\Pi_{i, t}^{f}+\Pi_{i, t}^{o} .
$$

We assume good $a$ is the numeraire and $p_{i, t}^{f}$ denotes the relative price of good $f$ in country $i$. Moreover, the relative price of the investment goods is equal to that of the non-oil good. $W_{i}^{j}$ is the wage rate and $R_{i}^{j}$ is the rental rate of capital in sector $j, j=a, f$, in country $i$. Households own the firms operating in the economy and hence receive profits from all sectors: $\Pi_{i, t}^{a}, \Pi_{i, t}^{f}$, and $\Pi_{i, t}^{o}$. Profits from the oil sector are given by $\Pi_{i, t}^{o}=\sum_{k} \Pi_{i, t}^{o k}$ where the three types of oil are denoted by $k=\mathrm{h}, \mathrm{l}$ or $\mathrm{m}$ for heavy, light and medium crude, respectively.

Investment in physical capital augments the capital stock $K_{i, t+1}^{j}, j=a, f$, according to the following laws of motion

$$
\begin{aligned}
& K_{i, t+1}^{f}=(1-\delta) K_{i, t}^{f}+I_{i, t}^{f}-\Phi\left(\frac{I_{i, t}^{f}}{K_{i, t}^{f}}\right) K_{i, t}^{f} \\
& K_{i, t+1}^{a}=(1-\delta) K_{i, t}^{a}+I_{i, t}^{a}-\Phi\left(\frac{I_{i, t}^{a}}{K_{i, t}^{a}}\right) K_{i, t}^{a}
\end{aligned}
$$


where $I_{i, t}^{j}$ denotes investment in sector $j=a, f$, and $\delta$ is the depreciation rate. Physical capital formation is subject to adjustment costs as in Baxter and Crucini (1995) [9] and Christiano, Eichenbaum and Evans (2005) [16]. Costs are governed by a quadratic investment adjustment cost function, $\Phi(\cdot)$, which takes the following form

$$
\Phi\left(\frac{I_{i, t}^{j}}{K_{i, t}^{j}}\right)=\frac{1}{2 \delta \phi_{i}}\left(\frac{I_{i, t}^{j}}{K_{i, t}^{j}}-v\right)^{2},
$$

where $j=a, f . \quad \phi_{i}>0$ governs the elasticity of investment-capital ratio with respect to Tobin's $q$, and $v$ denotes the steady state investment-capital ratio. Adjustment costs are incorporated to slow investment responses to shocks.

Finally, household's activities exhaust total hours available:

$$
\bar{L}_{i}-L_{i, t}-n_{i, t}^{a}-n_{i, t}^{f}=0
$$

where $\bar{L}_{i}$ is the total amount of time available for work and leisure in country $i$.

Each household earns labor income, capital income, and receives profits. In every period t, the household maximizes the utility function 3.1 with respect to consumption, labor supply, investment, and end-of-period capital stock subject to its budget constraint 3.2, the laws of motion for capital 3.3 and 3.4, and the time constraint 3.5. In doing so, prices and wages are taken as given.

\subsection{Firms and Production}

Each country produces three goods, crude oil, refined products, and a non-oil good, by perfectly competitive firms.

\subsubsection{Crude Oil Production (Light, Medium, Heavy)}

Each type of crude oil is produced by a representative profit-maximizing firm in country $i=1,2$. Oil production costs are in terms of the non-oil good and are an increasing function of oil production as in Balke, Plante, and Yucel (2015) [6]. We continue to denote the three oil types by $k=\mathrm{h}, \mathrm{l}$ or $\mathrm{m}$.

The oil producing firm chooses its oil production to maximize profits:

$$
\Pi_{i, t}^{o k}=p_{i, t}^{o k} y_{i, t}^{o k}-C_{i, t}^{k}
$$


where

$$
C_{i, t}^{k}=\frac{\left(\frac{y_{i, t}^{o k}}{z_{i, t}^{o k}}\right)^{1+\frac{1}{\eta_{i}^{k}}}}{1+\frac{1}{\eta_{i}^{k}}}
$$

denotes the production costs, representing the quantity of the non-oil good needed to produce a given amount of oil. These costs can be considered as (non-energy) inputs needed to produce oil, such as rigs. $y_{i, t}^{o k}$ is production of oil type $k$ and $z_{i, t}^{o k}$ represents a stochastic process for the evolution of productivity. Marginal costs increase with production increases, reflecting the difficulty of producing an additional unit of oil as oil production increases, and decreases with higher productivity. The firm sells its output to refineries at a price of $p_{i, t}^{o k}$. Profit maximization implies

$$
p_{i, t}^{o k}=\left(z_{i, t}^{o k}\right)^{-1}\left(\frac{y_{i, t}^{o k}}{z_{i, t}^{o k}}\right)^{\frac{1}{\eta_{i}^{k}}}
$$

where $\eta_{i}^{k}$ is country $i$ 's elasticity of supply for type $k$ oil. This suggests that the higher the elasticity of supply, the lower the marginal cost of producing a given amount of oil.

\subsubsection{Refined Products Production}

For the refining sector, we work with a production function in five inputs and restrict our attention to the class of constant elasticity of substitution production technologies. This type of production function is relatively simple and parsimonious, and gives a specification that allows for different elasticities of substitution across inputs.

We assume that the production function is a constant returns to scale CES of a capitallabor composite, itself a Cobb-Douglas function, and a composite of the three types of oil,

$$
y_{i, t}^{f}=\left[w_{i}^{f}\left(z_{i}^{f}\left(n_{i, t}^{f}\right)^{\chi_{i}^{f}}\left(K_{i, t}^{f}\right)^{1-\chi_{i}^{f}}\right)^{-\rho_{i}^{f}}+\left(1-w_{i}^{f}\right) G\left(o_{i, t}^{f l}, o_{i, t}^{f m}, o_{i, t}^{f h}\right)^{-\rho_{i}^{f}}\right]^{\frac{1}{-\rho_{i}^{f}}}
$$

where $z_{i}^{f}$ represents productivity in the sector, and $n_{i, t}^{f}, K_{i, t}^{f}$ denote labor and capital inputs. The parameter $w_{i}^{f}$ governs the share of value-added in gross output in country $i$, and $\chi_{i}^{f}$ governs the labor share in value-added in country $i$, with $0<w_{i}^{f}, \chi_{i}^{f}<1$. The elasticity of substitution between capital-labor composite and oil composite is $\frac{1}{1+\rho_{i}^{f}}$. Hence, we allow for the possibility that the cost-shares and productivity levels vary across countries, and 
allow for the fact that it is hard to substitute between oil and other inputs when it comes to producing fuel.

The function $G(\cdot)$ is a constant returns to scale CES aggregate of the three types of oil inputs, $o_{i, t}^{f l}, o_{i, t}^{f m}, o_{i, t}^{f h}$. Using a CES aggregator allows us to introduce the idea that the oils are imperfect substitutes for each other in a relatively parsimonious way. It also helps us capture differences in how much oil is being consumed by the refining sector of each country.

We choose to work with the following nested-CES function:

$$
G\left(o_{i, t}^{f l}, o_{i, t}^{f m}, o_{i, t}^{f h}\right)=\left[w_{i}^{o}\left(o_{i, t}^{f h}\right)^{-\rho_{i}^{o i l}}+\left(1-w_{i}^{o}\right)\left(\omega_{i}^{o}\left(o_{i, t}^{f l}\right)^{-\eta_{i}^{o i l}}+\left(1-\omega_{i}^{o}\right)\left(o_{i, t}^{f m}\right)^{-\eta_{i}^{o i l}}\right)^{\frac{\rho_{i}^{o i l}}{\eta_{i}^{o i l}}}\right]^{\frac{1}{-\rho_{i}^{o i l}}},
$$

where light and medium crudes form their own composite. The $w_{i}^{o}$ and $\omega_{i}^{o}$ terms are distribution parameters that control the relative use of the different types of oil in the sector. The elasticity of substitution between light oil (or medium oil) and heavy oil is $\frac{1}{1+\rho_{i}^{\text {oil }}}$, and the elasticity of substitution between light oil and medium oil is $\frac{1}{1+\eta_{i}^{\text {oil }}}$.

The use of this composite allows us to take a stand on whether light and medium crudes are more or less substitutable with each other than with heavy crude oil. This is motivated by the discussion in section 2 , where it was shown that the relative price of light crude to medium is much less volatile over time than the relative price of light to heavy. ${ }^{10}$ As we show later, allowing the elasticity to be different between light and medium vs. heavy will let us model this feature of the data. ${ }^{11}$

The representative producer of refined products in each country chooses $n_{i, t}^{f}, K_{i, t}^{f}, o_{i, t}^{f l}$, $o_{i, t}^{f m}$, and $o_{i, t}^{f h}$ to maximize profits

$$
\Pi_{i, t}^{f}=p_{i, t}^{f} y_{i, t}^{f}-W_{i, t}^{f} n_{i, t}^{f}-R_{i, t}^{f} K_{i, t}^{f}-p_{i, t}^{o l} o_{i, t}^{f l}-p_{i, t}^{o m} o_{i, t}^{f m}-p_{i, t}^{o h} o_{i, t}^{f h}
$$

subject to equations 3.6 and 3.7. In solving this problem, the producer takes as given the wage $W_{i, t}^{f}$, the rental price of capital $R_{i, t}^{f}$, and the prices of light, medium and heavy

\footnotetext{
${ }^{10}$ The higher volatility of the relative price of light to heavy oil could also be due to differences in the volatility of supply shocks to medium or heavy crude. Data limitations prevent us from investigating this possibility.

${ }^{11}$ Another signal that the two are more substitutable is that the prices of light and medium are typically much closer to each other than they are to heavy crude oil. The processing of heavy crude oil also generally requires some very specific capital, such as cokers, which are not required to process other oils.
} 
oil $p_{i, t}^{o l}, p_{i, t}^{o m}, p_{i, t}^{o h}$. The representative firm sells its output to households and non-oil good producers at a price $p_{i, t}^{f}$.

\subsubsection{Non-oil Good Production}

Finally, a representative firm hires labor and rents capital from the household and purchases refined products from refineries to produce non-oil good. In doing so, it uses a constant returns to scale technology that combines a capital-labor composite with refined products. The production function is

$$
y_{i, t}^{a}=\left[w_{i}^{a}\left(z_{i, t}^{a}\left(n_{i, t}^{a}\right)^{\chi_{i}^{a}}\left(K_{i, t}^{a}\right)^{1-\chi_{i}^{a}}\right)^{-\rho_{i}^{a}}+\left(1-w_{i}^{a}\right)\left(m_{i, t}^{f}\right)^{-\rho_{i}^{a}}\right]^{\frac{1}{-\rho_{i}^{a}}}
$$

where $z_{i, t}^{a}$ represents a stochastic process for the evolution of productivity, $n_{i, t}^{a}, K_{i, t}^{a}$ denote labor and capital inputs, and $m_{i, t}^{f}$ is the input of refined products. The parameter $\chi_{i}^{a}$ controls the share of labor in non-oil sector's value-added in country $i, w_{i}^{a}$ controls the relative use

of capital-labor composite and refined products in the sector, and $\frac{1}{1+\rho_{i}^{a}}$ is the elasticity of substitution between capital-labor composite and refined products. The firm chooses $n_{i, t}^{a}, K_{i, t}^{a}$, and $m_{i, t}^{f}$ to maximize profits

$$
\Pi_{i, t}^{a}=y_{i, t}^{a}-W_{i, t}^{a} n_{i, t}^{a}-R_{i, t}^{a} K_{i, t}^{a}-p_{i, t}^{f} m_{i, t}^{f}
$$

subject to equation 3.8. The producer sells its output to households and oil producers.

\subsection{Market Clearing}

A competitive equilibrium for the world economy requires market clearing for all the goods, i.e. that production of each good must equal the total use of that good,

$$
\begin{gathered}
y_{1, t}^{o l}+y_{2, t}^{o l}=o_{1, t}^{f l}+o_{2, t}^{f l}, \\
y_{1, t}^{o m}+y_{2, t}^{o m}=o_{1, t}^{f m}+o_{2, t}^{f m} \\
y_{1, t}^{o h}+y_{2, t}^{o h}=o_{1, t}^{f h}+o_{2, t}^{f h} \\
y_{1, t}^{f}+y_{2, t}^{f}=c_{1, t}^{f}+c_{2, t}^{f}+m_{1, t}^{f}+m_{2, t}^{f}, \\
y_{1, t}^{a}+y_{2, t}^{a}=c_{1, t}^{a}+c_{2, t}^{a}+I_{1, t}^{a}+I_{2, t}^{a}+I_{1, t}^{f}+I_{2, t}^{f}+C_{1, t}^{l}+C_{2, t}^{l}+C_{1, t}^{m}+C_{2, t}^{m}+C_{1, t}^{h}+C_{2, t}^{h} .
\end{gathered}
$$


Trade balances every period. All the goods can be traded freely and no trade costs are assumed, so both purchasing power parity (PPP) and law of one price hold:

$$
\begin{gathered}
p_{1, t}^{o l}=p_{2, t}^{o l}, \\
p_{1, t}^{o m}=p_{2, t}^{o m}, \\
p_{1, t}^{o h}=p_{2, t}^{o h}, \\
p_{1, t}^{f}=p_{2, t}^{f} .
\end{gathered}
$$

\section{Calibration and solution method}

\subsection{Calibration}

We solve the model numerically, which requires us to calibrate the model. ${ }^{12}$ Our model is calibrated at an annual frequency. Country 1 represents the U.S. while country 2 represents the rest of the world. Our main data sources are the U.S. Energy Information Administration, the Oil and Gas Journal, the International Energy Agency, the Bureau of Labor Statistics, the Bureau of Economic Analysis, the International Monetary Fund, the United Nations, Bloomberg, World Input Output Database (WIOD), and Eni's 2017 World Oil and Gas Review. Appendix A contains a complete description of the data series used in the calibration.

We choose the starting values for a number of the model's variables and calibrate some parameters to match certain moments of the data. Where possible, we calibrate an initial steady state to match data from 2010, as this is the year before oil production in the U.S. started booming. In certain cases, the steady state is chosen to match time-series averages of the data. A number of parameters and starting values are then determined implicitly through the steady state equations. Finally, the parameters for the shock processes, along with several model parameters, are calibrated using simulated method of moments. The starting values and moments used in the model calibration are shown in Table 4.1. Table 4.2 presents the values of the model's parameters. A discussion of the moment-matching exercise is deferred until later.

\footnotetext{
${ }^{12}$ We use the Dynare software package developed by Adjemian et al. (2011) [1] to solve our model.
} 
Several parameters related to preferences, capital accumulation and production functions are calibrated to be equal across countries. The discount factor $\beta$ is set 0.96 . The depreciation rate of capital, $\delta$, is set to 0.10 . We set the capital adjustment cost parameter, $\phi$, to 4 , in line with Christiano, Eichenbaum and Evans (2005) [16]. The curvature parameter determining the household's coefficient of relative risk aversion, $\gamma$, is set at -1 , as in Backus and Crucini (2000) [3] or Backus, Kehoe and Kydland (1994) [5]. The elasticity of substitution between refined petroleum products and the non-oil good consumption, given by $\frac{1}{1+\rho}$, is set at 0.20 . This produces a low price elasticity of demand for refined products, with a value that is within the range of the literature. ${ }^{13}$ Following Bodenstein, Erceg and Guerrieri (2011) [11], we constrain this elasticity to be equal for households and firms in both countries. The elasticity of supply of oil is set to 0.13, consistent with Bornstein, Krusell and Rebelo (2017) [13]. This ensures that supply of oil is fairly inelastic in response to price changes, a key feature of the data.

Without loss of generality, we normalize U.S. GDP to 1, which allows us to calibrate several variables in terms of GDP-ratios. The total time available in the U.S., $\bar{L}_{1}$ is normalized to 1. The share of world GDP due to the U.S. was $17 \%$ in 2010 and the U.S. population share was $4.5 \%$, based on UN data. We use these facts to calibrate ROW GDP and the total time available in ROW, $\bar{L}_{2}$. For both the U.S. and ROW, we assume an average time allocation of $\frac{2}{3}$ to leisure.

The relative price of fuel, $p^{f}$, is also normalized to 1 . We set $c_{1}^{f}$ equal to $2.2 \%$ of U.S. GDP, based on data from the BEA for household spending on gasoline and heating oil in 2010. Non-household petroleum spending in the U.S., $m_{1}^{f}$, is set to $2.2 \%$ of GDP, based on BEA and EIA data.

The calibration for household and firm petroleum use in ROW is obtained using data from several sources. The World Input Output Database (WIOD) provides data on "coke and refined petroleum products" by firms as an intermediate input and also final consumption of the good by households for 40 countries. ${ }^{14}$ The EIA provides data on world consumption of petroleum and other liquids by region and end-use sector. Finally, Exxon 2016 Energy

\footnotetext{
${ }^{13}$ For example, see the discussion in Baumeister and Hamilton (2016) [7].

${ }^{14}$ See Timmer et al. (2015) [39] for details on the database.
} 
Table 4.1: Baseline Calibration: Targets

U.S.

\begin{tabular}{|c|c|c|}
\hline Description & Symbol & Value \\
\hline GDP & $y_{1}^{g}$ & 1 \\
\hline Fuel prices & $p_{1}^{f}$ & 1 \\
\hline Total time & $\bar{L}_{1}$ & 1 \\
\hline Time allocated to leisure & $L_{1}$ & $2 / 3$ \\
\hline Household fuel use & $c_{1}^{f}$ & 0.022 \\
\hline Firm fuel use & $m_{1}^{f}$ & 0.022 \\
\hline Fuel production & $y_{1}^{f}$ & $0.995\left(c_{1}^{f}+m_{1}^{f}\right)$ \\
\hline Total oil production & $y_{1}^{o}=y_{1}^{o l}+y_{1}^{o m}+y_{1}^{o h}$ & $0.35 y_{1}^{f}$ \\
\hline Light oil production & $y_{1}^{o l}$ & $0.390 y_{1}^{o}$ \\
\hline Medium oil production & $y_{1}^{o m}$ & $0.504 y_{1}^{o}$ \\
\hline Heavy oil production & $y_{1}^{o h}$ & $0.106 y_{1}^{o}$ \\
\hline Total oil input to refiners & $o_{1}^{f}=o_{1}^{f l}+o_{1}^{f m}+o_{1}^{f h}$ & $2.675 y_{1}^{o}$ \\
\hline Light oil used by refiners & $o_{1}^{f l}$ & $0.286 o_{1}^{f}$ \\
\hline Medium oil used by refiners & $o_{1}^{f m}$ & $0.415 o_{1}^{f}$ \\
\hline Heavy oil used by refiners & $o_{1}^{f h}$ & $0.299 o_{1}^{f}$ \\
\hline Relative price of light oil to medium & $p^{o l} / p^{o m}$ & 1.06 \\
\hline Relative price of light oil to heavy & $p^{o l} / p^{o h}$ & 1.18 \\
\hline Cost-share of oil in refining & $\sum_{k}^{k=l, m, h}\left(p^{o k} o_{1}^{f k}\right) /\left(p_{1}^{f} y_{1}^{f}\right)$ & 0.774 \\
\hline \multicolumn{3}{|c|}{ ROW } \\
\hline GDP & $y_{2}^{g}$ & $83 \%$ of world GDP \\
\hline Total time & $\bar{L}_{2}$ & $95.5 \%$ of world population \\
\hline Time allocated to leisure & $L_{2}$ & $2 / 3 \bar{L}_{2}$ \\
\hline Total oil production & $y_{2}^{o}=y_{2}^{o l}+y_{2}^{o m}+y_{2}^{o h}$ & $0.927 \%$ of world total \\
\hline Light oil production & $y_{2}^{o l}$ & $0.300 y_{2}^{o}$ \\
\hline Medium oil production & $y_{2}^{o m}$ & $0.559 y_{2}^{o}$ \\
\hline Heavy oil production & $y_{2}^{o h}$ & $0.141 y_{2}^{o}$ \\
\hline Total fuel production & $y_{2}^{f}$ & $1.017 o_{2}^{f}$ \\
\hline Household fuel use & $c_{2}^{f}$ & $1 / 2$ of firm use \\
\hline
\end{tabular}


Table 4.2: Baseline Calibration: Parameter values

Shared parameters

\begin{tabular}{|c|c|c|}
\hline Description & Symbol & Parameter value \\
\hline Discount factor & $\beta$ & 0.96 \\
\hline Curvature parameter in utility function & $\gamma$ & -1 \\
\hline Depreciation rate of capital & $\delta$ & 0.10 \\
\hline Elasticity of investment-capital ratio w.r.to Tobin's $q$ & $\phi$ & 4 \\
\hline Elasticity of substitution (fuel, non-oil good) & $1 /(1+\rho)$ & 0.20 \\
\hline Elasticity of substitution in refining (light, medium crude) & $1 /\left(1+\eta^{o i l}\right)$ & 3.65 \\
\hline Elasticity of substitution in refining (heavy, composite) & $1 /\left(1+\rho^{o i l}\right)$ & 2.13 \\
\hline Elasticity of substitution in refining (value-added, oil) & $1 /\left(1+\rho^{f}\right)$ & 0.285 \\
\hline Elasticity of oil supply, for $k=l, m, h$ & $\eta^{k}$ & 0.13 \\
\hline \multicolumn{3}{|l|}{ U.S. } \\
\hline Weight on value-added in refining production & $w_{1}^{f}$ & .9578 \\
\hline Labor's share in refining value-added & $\chi_{1}^{f}$ & 0.164 \\
\hline Weight on $o_{1}^{f l}$ in refining production & $\omega_{1}^{o}$ & 0.4891 \\
\hline Weight on $o_{1}^{f h}$ in refining production & $w_{1}^{o}$ & 0.2891 \\
\hline Labor's share in non-oil production & $\chi_{1}^{a}$ & 0.60 \\
\hline Weight on fuel in non-oil production & $\left(1-w_{1}^{a}\right)$ & $5.1382 e-09$ \\
\hline Weight on fuel in utility function & $\left(1-w_{1}\right)$ & $3.1589 e-08$ \\
\hline Weight on leisure in utility function & $\mu_{1}$ & 0.3787 \\
\hline \multicolumn{3}{|l|}{ ROW } \\
\hline Weight on value-added in refining production & $w_{2}^{f}$ & 0.9334 \\
\hline Labor's share in refining value-added & $\chi_{2}^{f}$ & 0.297 \\
\hline Weight on $o_{2}^{f l}$ in refining production & $\omega_{2}^{o}$ & 0.471 \\
\hline Weight on $o_{2}^{f h}$ in refining production & $w_{2}^{o}$ & 0.1784 \\
\hline Labor's share in non-oil production & $\chi_{2}^{a}$ & 0.55 \\
\hline Weight on fuel in non-oil production & $\left(1-w_{2}^{a}\right)$ & $7.4458 e-09$ \\
\hline Weight on fuel in utility function & $\left(1-w_{2}\right)$ & $1.5165 e-09$ \\
\hline Weight on leisure in utility function & $\mu_{2}$ & 0.3935 \\
\hline
\end{tabular}


Outlook [21] provides data on world oil use by end-use sector. Based on our calculations using different sources, we assume a ratio of 0.50 for the ratio of household use of petroleum to firm use for 2010, allowing us to pin down steady state values of household use and firm use of refined products for the ROW.

We rely on data from the World Input Output Database to calibrate the labor-share of value-added in the non-oil sector, given by $\chi_{1}^{a}$ and $\chi_{2}^{a}$. The database provides annual data on labor compensation and total value-added for 40 countries (including the U.S.), with the time series running from 1995 to 2011 for most countries. We use this data to generate a time series for the labor share of total value-added in each country and take an average over $2000-2009$. The value for the U.S. is obtained as $\chi_{1}^{a}=0.60$. To get the labor share of total value-added for the ROW, we find the share of global GDP due to each country, excluding the U.S., and use these shares to weight each country's average labor-share. We then sum the weighted labor shares to get our estimate for the ROW, $\chi_{2}^{a}=0.55$.

U.S. refined products production equaled $99.5 \%$ of total domestic refined products consumption in 2010, which we use to set $y_{1}^{f}$. The total volume of crude oil processed by U.S. refiners that year was about $93.6 \%$ of total U.S. refinery production. ${ }^{15}$ To determine the shares of each type of oil processed in the U.S. refineries, we use the estimates presented in subsection 2.4. These shares determine the starting values for $o_{k_{1}}^{f}$ for $k=l, m, h$. Total ROW fuel production, $y_{2}^{f}$, is set to match data on refinery gains for the ROW that come from the EIA and IEA.

We set total U.S. oil production to match the fact that U.S. production in 2010, in mb/d, was $35 \%$ of U.S. refinery output of fuel. The U.S. share in global oil production in 2010 was 0.073, which determines total ROW oil production. The steady state values of light, medium, and heavy oil production for both the U.S. and ROW are set to match the shares of each type of oil in total production, based on Eni data presented in subsection 2.2.

Oil price data is used to set two moments in the model, the relative price of light oil to medium and the relative price of light oil to heavy. As a proxy for light, medium and heavy oil prices, we consider LLS, Dubai and Maya prices, respectively. ${ }^{16}$ We construct annual

\footnotetext{
${ }^{15}$ This is due to a volumetric expansion that occurs when crude oil is processed into refined petroleum products.

${ }^{16}$ Due to data limitations, we use Dubai for medium oil price, not Mars in our calibration. They both
} 
averages for relative oil prices using monthly data from Bloomberg, and set the steady state price ratios to their 2010 averages.

We match the average cost share of crude oil in gasoline and diesel prices in the U.S. for $2010,77.4 \%$, to determine the weight $w_{1}^{f}$. For the labor share of value-added in the refining sector, $\chi_{1}^{f}$ and $\chi_{2}^{f}$, we rely on data from the World Input Output Database. This database provides annual data on labor compensation and value-added in the petroleum and coal products sector for 38 countries (including the U.S.), and covers about $75 \%$ of global refining capacity. We generate a time series for the labor share of value-added for each country and find the average labor share over 2000 - 2009. The value for the U.S. is obtained as 0.164. To get the ROW labor share, we used data from the Oil\&Gas Journal on refining capacity in 2010 to find the share of refining capacity in each country out of the total excluding the U.S. We use these shares to weight each country's labor-share and sum across these countries to get our estimate for the ROW, 0.297. This implies that U.S. refining sector is more capital intensive than the ROW refining sector.

In our calibration, the oil and fuel trade balances match 2010 data for the U.S., which implicitly determines the non-oil trade balance at the steady state as we have abstracted from financial assets in the model.

\subsection{Moment-matching exercise}

The parameters governing the autoregressive processes for the productivity shocks are not determined by the deterministic steady state. We also need to calibrate the elasticities of substitution across different oil inputs, given by $\eta^{\text {oil }}$ and $\rho^{\text {oil }}$, as well as the elasticity of substitution between value-added and oil in the refining production function, given by $\rho^{f}$. To calibrate these parameters, we use simulated method of moments, a standard technique in the business cycle literature, to have the model match several time-series properties of the data.

We use data on U.S. and ROW real GDP as well as U.S. and ROW crude oil production to help guide the calibration of the shocks. The ROW GDP series is an index of the tradehave similar API gravity, and the coefficient of variations for LLS to Mars price ratio and LLS to Dubai price ratio are roughly the same, 0.055 and 0.056 over $1997-2016$, respectively. 
weighted average of GDP series for 40 countries from the Database of Global Economic Indicators. ${ }^{17}$ Data on U.S. and ROW oil production are based on the EIA World Crude Oil Production Including Lease Condensate series. We would have preferred to use time series data on oil production by type but we do not have a sufficiently long time series available, even for the U.S. We average the monthly and quarterly observations for oil production and GDP, respectively, to produce an annual time series and then take the log of the annual series.

As we do not explicitly model trends in economic variables, oil or otherwise, we de-trend the data using a one-sided HP filter. For the oil production and refiner input series we filter the entire sample from 1973 to 2016. For the GDP series, we start the filter in 1981, as this is the first year for which we have an annual average for ROW GDP.

The left and right panels of Figure 4.1 plot the de-trended data series for GDP and oil production, respectively. The gray bars in the GDP figure denote NBER recessions. We note that the GDP series picks up the Great Recession, U.S. recessions in the early 1990s and early 2000s, and the above trend growth in the ROW GDP in the mid-2000s due to the BRICs. The de-trended oil production series clearly show the impact of the shale boom and subsequent production decline in the U.S., as well as the long period from 2005 to 2013 where production outside the U.S. remained range-bound between about 68 to 70 million barrels per day.

In our calibration exercise, we constrain the autocorrelations and volatilities of the productivity shocks for different oil types to be equal, although they can differ between the U.S. and ROW. Ideally, we would prefer to allow these to be different across types within countries but we do not have a sufficiently long time series to do this. This leaves a total of 8 parameters that need to be calibrated for the shocks.

We choose 8 moments from the de-trended data to calibrate the parameters: the firstorder autocorrelations and the volatilities of each data series. Our goal in the exercise is to calibrate the shock parameters so as to have the model simulated data match these moments in the data. We trim the sample to run from 1986 to 2010. We remove data after 2010 to remove the influence of the shale boom, as we want to treat that as the "shock" in our DSGE

\footnotetext{
${ }^{17}$ See Grossman et al. (2014) [23] for more details.
} 
Figure 4.1: De-trended GDP and oil production, U.S. vs. the ROW

Log GDP

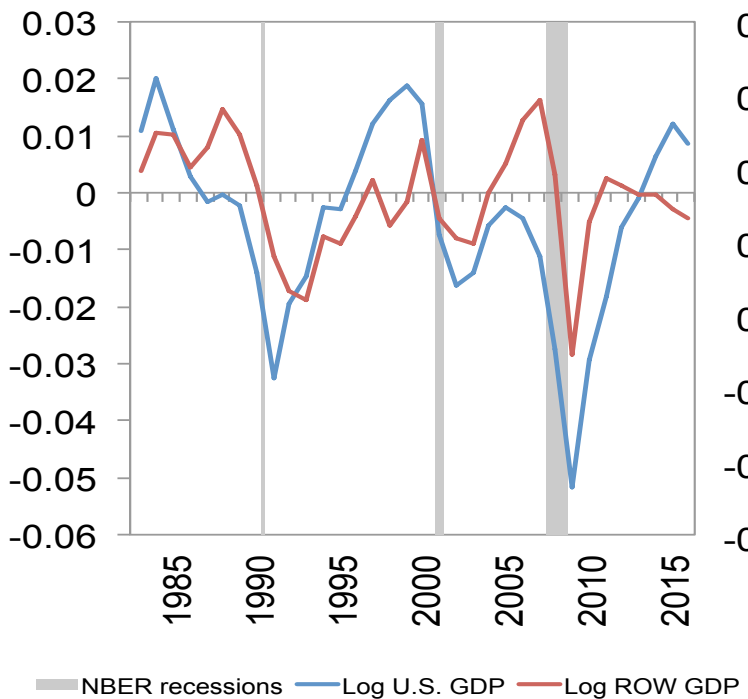

Log oil production

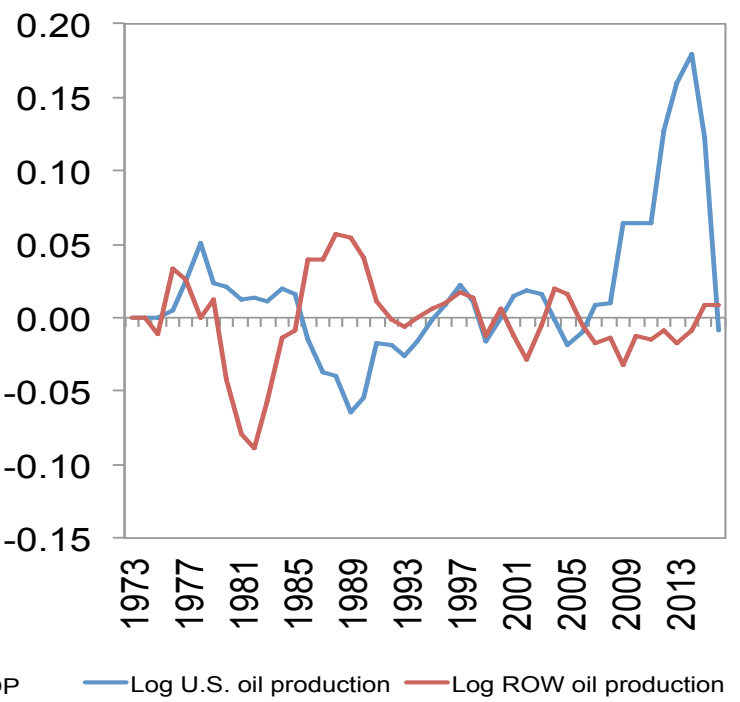

Sources: Bureau of Economic Analysis; Database of Global Economic Indicators; Energy Information Administration; authors' calculations.

model. We start in 1986 to start our oil production series following the collapse of OPEC production cuts around that time.

We jointly estimate those 8 parameters with the elasticities. We constrain the elasticities to be equal across countries, so there are a total of three that need to be calibrated. We use three moments in the data as targets for the calibration: the correlation between (real) light and medium oil prices, the correlation between (real) light and heavy oil prices, and the volatility of total crude oil inputs to U.S. refiners. We have chosen these moments as the elasticities in the model play a key role in determining the values of those moments in model-simulated data. For the oil price data, we use annual price data on LLS, Dubai and Maya crude oils from 1991 to 2016. We start in 1991 as this is the first year for which we have regular price data on heavy crude oil (Maya). The refiner input series is obtained from the EIA and runs from 1973 to 2016. As with the GDP and oil production series, we filter the data using a one-sided HP filter, and then calculate the statistics of interest from the filtered data.

The results of the moment matching exercise for the shock parameters are presented in Table 4.3. And, the moments are reported in Table 4.4, which compares the properties of 
Table 4.3: Calibration of shock parameters

\begin{tabular}{lcc} 
Shock type & AR(1) coefficient & Volatility \\
\hline \hline Technology (U.S.) & .614 & .0087 \\
Technology (ROW) & .371 & .0074 \\
Oil supply (U.S.) & .694 & .0279 \\
Oil supply (ROW) & .737 & .0325 \\
\hline
\end{tabular}

the model to actual data. In terms of matching the targeted moments, the model does a good job. It closely replicates the observed volatilities of U.S. and ROW oil supply and GDP, and the observed volatility of total crude oil inputs to U.S. refiners. The model's ability to match the (non-targeted) light oil price volatility is weaker, but still the model can account for about $60 \%$ of the light oil price volatility. We note that other works that use a similar modeling framework, such as Bodenstein, Erceg and Guerrieri (2011) [11], also have trouble matching oil price volatility at business cycle frequencies.

Our exercise leads to an elasticity between light and medium $\left(\frac{1}{1+\eta^{o l i}}\right)$ of 3.65 and the elasticity between heavy and composite $\left(\frac{1}{1+\rho^{o i l}}\right)$ at 2.13. Light and medium oil are more substitutable with each other than with heavy oil, in line with our intuition. The value for the elasticity between value-added and oil, at a very low value of 0.285 , is also in line with our intuition, i.e. it is very difficult to substitute between oil and other inputs in the production of refined petroleum products.

\section{Results}

We model the shale oil boom as an exogenous shock that lowers the cost of producing light oil in the U.S., i.e. a positive shock to $z_{1, t}^{o L}$. In order to generate a path for the shocks, we conduct the following exercise. We have data on the annual percent change in U.S. light oil production from 2010 to 2015 . We numerically solve for the values of the productivity shocks that would generate the same percentage changes in the model. We then feed these shocks into the model and analyze how various variables respond to the increased light oil 
Table 4.4: Properties of the key variables, Data vs Model

\begin{tabular}{lcccc} 
& \multicolumn{2}{c}{ Data } & \multicolumn{2}{c}{ Model } \\
Variable & Autocorrelation/ & \multicolumn{2}{c}{ Autocorrelation/ } \\
Correlation & Volatility & Correlation & Volatility \\
\hline \hline U.S. oil production (total) & 0.698 & 0.03 & 0.698 & 0.03 \\
ROW oil production (total) & 0.737 & 0.024 & 0.737 & 0.024 \\
U.S. GDP & 0.714 & 0.016 & 0.712 & 0.016 \\
ROW GDP & 0.495 & 0.011 & 0.495 & 0.011 \\
\hline U.S. refiner inputs/runs (total) & & 0.024 & & 0.024 \\
light and medium oil prices & 0.981 & & 0.981 & \\
light and heavy oil prices & 0.954 & & 0.954 & \\
\hline Log of light oil price & & 0.154 & & 0.093 \\
\hline
\end{tabular}

production.

Given the large number of variables in the model, we choose to focus on a subset of the results of particular interest and importance in the paper. Figure 5.1 shows impulse responses of the important variables from the oil market and the broader economy to a light oil productivity shock. Figure 5.2 shows impulse responses of additional variables primarily related to the oil and refining sectors. Units are percentage deviations of each variable from its starting point, calibrated in most cases to line up with 2010 data.

The top left panel of Figure 5.1 shows the path of U.S. light oil production, which by default lines up with the data. Total U.S. production rises by about 75 percent by 2015 . The rise in U.S. oil production induces a small decline in oil production outside the U.S. which falls by more than 2 percent. The increase in U.S. oil production pushes world oil production up by around 3.7 percent by 2015 .

The increased light oil supply reduces the price of light oil by 20 percent by 2015 . The decline is the same in the U.S. and ROW, as there is free trade in crude. The price of light crude falls by more than the prices of medium and heavy crudes, as shown by Figure 5.2 bottom row, as the supply increase is solely in light crude oil. Given that crude oil is only 
used in the refining sector to produce fuel and that it accounts for a bulk of the cost of producing fuel, world fuel prices fall, by around 14 percent. However, the increase in light oil use by U.S. refiners is not enough to absorb all the new light oil production so there is a sharp decline in imports of light crude. Indeed, the supply increase is large enough to make the U.S. a net exporter of light crude oil in 2013. As refiners substitute away from medium and heavy crudes, both imports and uses of medium and heavy crudes by U.S. refiners decline.

The lower relative price of light oil leads to more processing of light crude by both U.S. and ROW refiners. Light and medium crudes are closer substitutes for each other than with heavy crude oil, hence medium oil inputs into the refinery process decline more than heavy oil inputs. Moreover, fuel prices declining less than light oil prices creates the incentive for refiners to process more light oil and produce fuel. Hence, refined products production in both the U.S. and the ROW increases. But, the increase in ROW production is much larger than the increase in U.S. fuel production, as ROW refineries have a relative advantage in processing light oil. U.S. fuel production is about 0.7 percent higher in 2015 than 2010, while ROW fuel production is up almost 4 percent.

The decline in oil imports translates into an improved oil trade balance. The U.S. oil trade balance as a share of GDP improves by more than one percentage point by 2015 . With higher production of fuel in the ROW, the U.S. imports more fuel as demand is higher, hence the U.S. fuel trade balance as a share of GDP slightly deteriorates. Overall, there is a substantial improvement in total petroleum trade balance, as it is driven primarily by oil.

Turning to the broader economy, we find that cheaper fuel prices increase household fuel consumption by about 4.0 percent and aggregate consumption by around 1.2 percent. Although not presented in the figures, lower fuel prices also boost firm fuel use, which leads to an increase in marginal product of capital, causing investment and non-oil output to increase. Although the oil and gas sector is less than 1.5 percent of GDP, the shale boom has a substantial effect on the broader economy. Overall, the increase in light oil production boosts U.S. GDP by more than 1.0 percent in 2015 versus 2010 levels. Given that the increase in U.S. GDP was 10.8 percent from 2010 to 2015, the effect of the shale boom is significant, at about one tenth of growth. 
Figure 5.1: Impulse responses to a light oil productivity shock, baseline (no export ban)
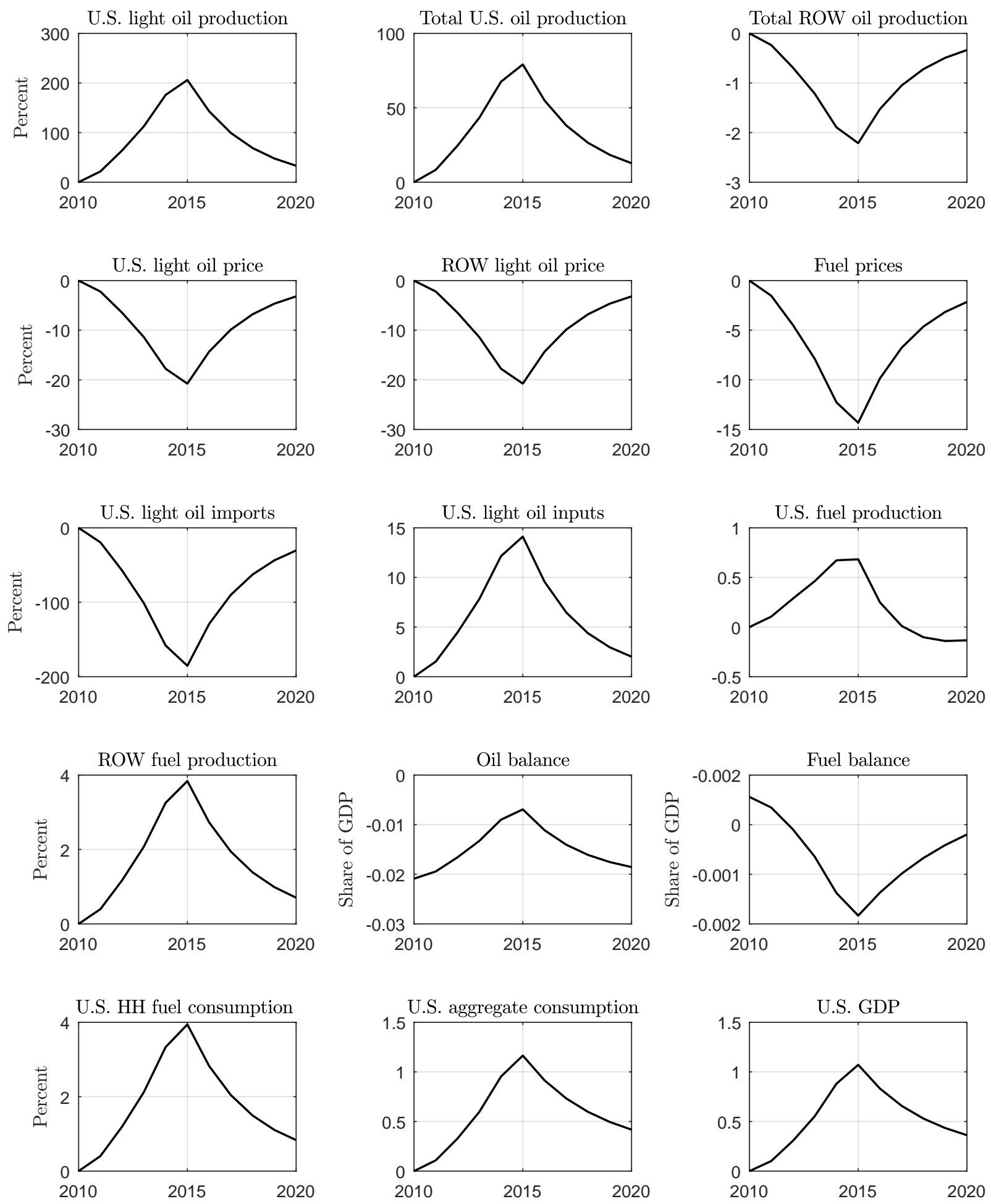

Note: Units are percent deviations from the steady state. 
Figure 5.2: Impulse responses to a light oil productivity shock, baseline (no export ban)
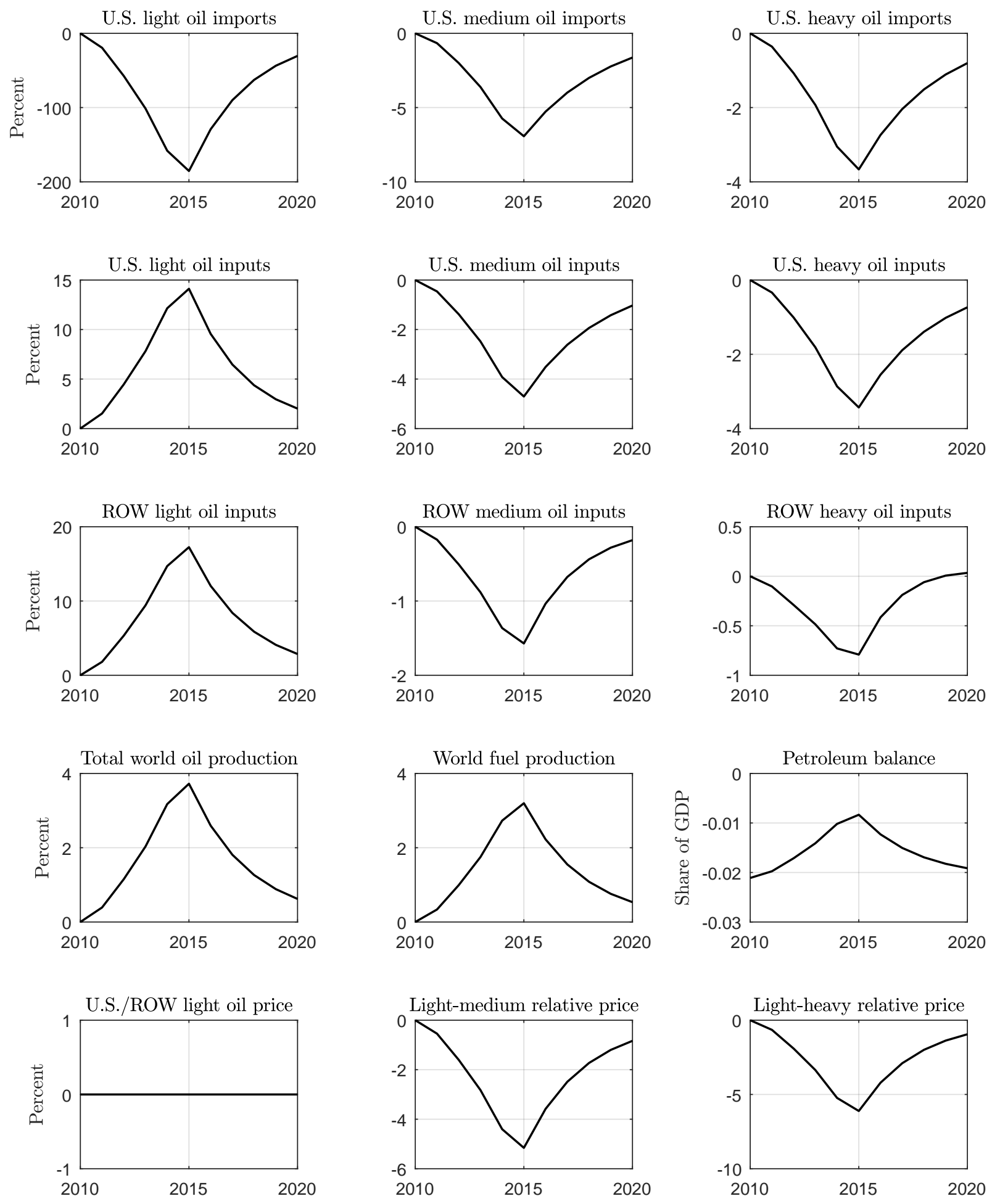

Note: Units are percent deviations from the steady state. 


\section{The Extended Model: Impact of the Crude Oil Ex- port Ban}

In our framework presented in Section 3, there are no restrictions on trade. During most of the shale boom, though, a crude oil export ban was in place. We extend our baseline model to incorporate the U.S. crude oil export ban as follows. The export ban is modeled as an exogenously given constraint that prevents (net) imports of all types of crude oil in the U.S. from becoming negative, i.e. exports are impossible. At its most basic level, this means having inequality constraints in the model, one for each type of oil. These constraints are given by

$$
o_{k_{1, t}}^{f}-y_{1, t}^{o k} \geq 0
$$

for $k=h, m, l$. Further mathematical details about how we set up the export ban can be found in the Appendix B.

We point out several important facets of this constraint using the case of light oil as an example. First, if the constraint binds, then part of the oil market in the U.S. becomes segmented from the rest of the world. This would create a wedge between domestic light oil prices and foreign light oil prices. Second, the constraint itself is endogenous in the sense that both refiner use of light oil and production of light oil are endogenous variables. For example, the ability of refiners to substitute away from using other oils towards light oil has implications for when the constraint might bind and what kind of price differentials it is likely to generate.

To solve the model with inequality constraints, we use the Guerrieri and Iacoviello (2015) [24] OccBin toolkit for Dynare, allowing us to examine the possibility that the export ban could bind for some period of time. The length of the time is endogenously determined by the shocks that hit the economy and the structure of the economy.

\subsection{Results}

Our goal is to investigate the potential effects of the U.S. oil export ban, both on oil markets and the broader economy. Our experiment is the same as in the previous section. We 
start from an initial steady state and feed in a series of positive light oil supply shocks that replicate the actual path of the change in U.S. light oil production seen in the data from 2010 to 2015. To briefly highlight our findings, the extended model predicts that the ban was binding for several years and distorted a number of economic outcomes, particularly those related to the refining sector.

Figures 6.1 and 6.2 show the impulse responses of the same set of variables presented in Figures 5.1 and 5.2, respectively. The solid lines show the model with free trade case while the dashed lines show the responses in the model that accounts for the ban.

We first turn to the most basic question: was the ban binding at any point in time? Our model says yes, primarily in 2014 and 2015 but also to a small extent in 2013. The extended model also suggests that the ban would have remained a constraint on the economy in 2016 given the expected path of oil production.

We next ask to what extent the ban affected economic outcomes. We find that the implications of the ban are relatively important for oil prices. The price of light crude oil in the U.S. becomes artificially cheap relative not only to light crude oil in the ROW, but also compared to other grades of crude oil. We note that the model predicts a decline of about 27 percent in U.S. light oil prices, compared to a 20 percent decline in the model with free trade. Likewise, the decline in the relative prices of light to both medium and heavy crudes is more than 5 percentage points greater than in case of free trade.

Since oil supply elasticities are very low, the price distortions generated by the ban have only minor implications for crude production levels. U.S. oil production is slightly lower with ban in place, while ROW production is slightly higher.

With exports prohibited, refiners must be incentivized to absorb the excess supply when the export ban binds. The discounts that emerge between light oil in the U.S. and the rest of world, as well as against other grades of crude, is the needed incentive. The oil price discount leads to a significantly higher use of light oil by U.S. refiners than occurs under the model with free trade. This increased use of light oil crowds out the use of medium crude by U.S. refiners, and reduces the amount of light crude processed by ROW refiners, relative to the free trade case.

U.S. refiners produce significantly more refined petroleum product when the ban binds. 
Extra production from the U.S. crowds out fuel production by ROW refiners and, in fact, we find that world fuel production is essentially the same whether the export ban is taken into account or not. As a result, the impact of the crude oil ban on fuel prices is negligible since there is always free trade in refined petroleum products.

With the export ban in place, the improvement in the U.S. oil balance is lower than the free trade case. The U.S. oil trade balance as a share of GDP goes up from a deficit of 2 percent in 2010 to a deficit of 1 percent in 2015, very close to what we observe in the data. Compared to the free trade case, the U.S. produces more fuel and becomes a net exporter of refined products by 2014 in the model. The overall balance sees a very small improvement relative to the free trade case.

Although the oil ban creates substantial distortions in the refining sector, the spillovers to the broader economy appear limited. There is essentially no impact on fuel consumption, and a minor impact on aggregate consumption and real GDP.

Finally, in Table 6.1, we focus on how several variables have changed from 2010 to 2015 in the data, and compare those changes with the changes predicted by the model. By default, U.S. light oil production in the model grows by exactly the same amount as the data. The model generates a 27 percent decrease in light oil prices, somewhat smaller than the decline seen in the data. We find the fall in net oil imports and increase in U.S. light refiner inputs in the model are very close to changes in the data. Overall, the model has done a good job in explaining some of the changes seen in the data despite the fact that we only relied on a single shock to generate these changes. 
Figure 6.1: Impulse responses to a light oil productivity shock, with and without export ban
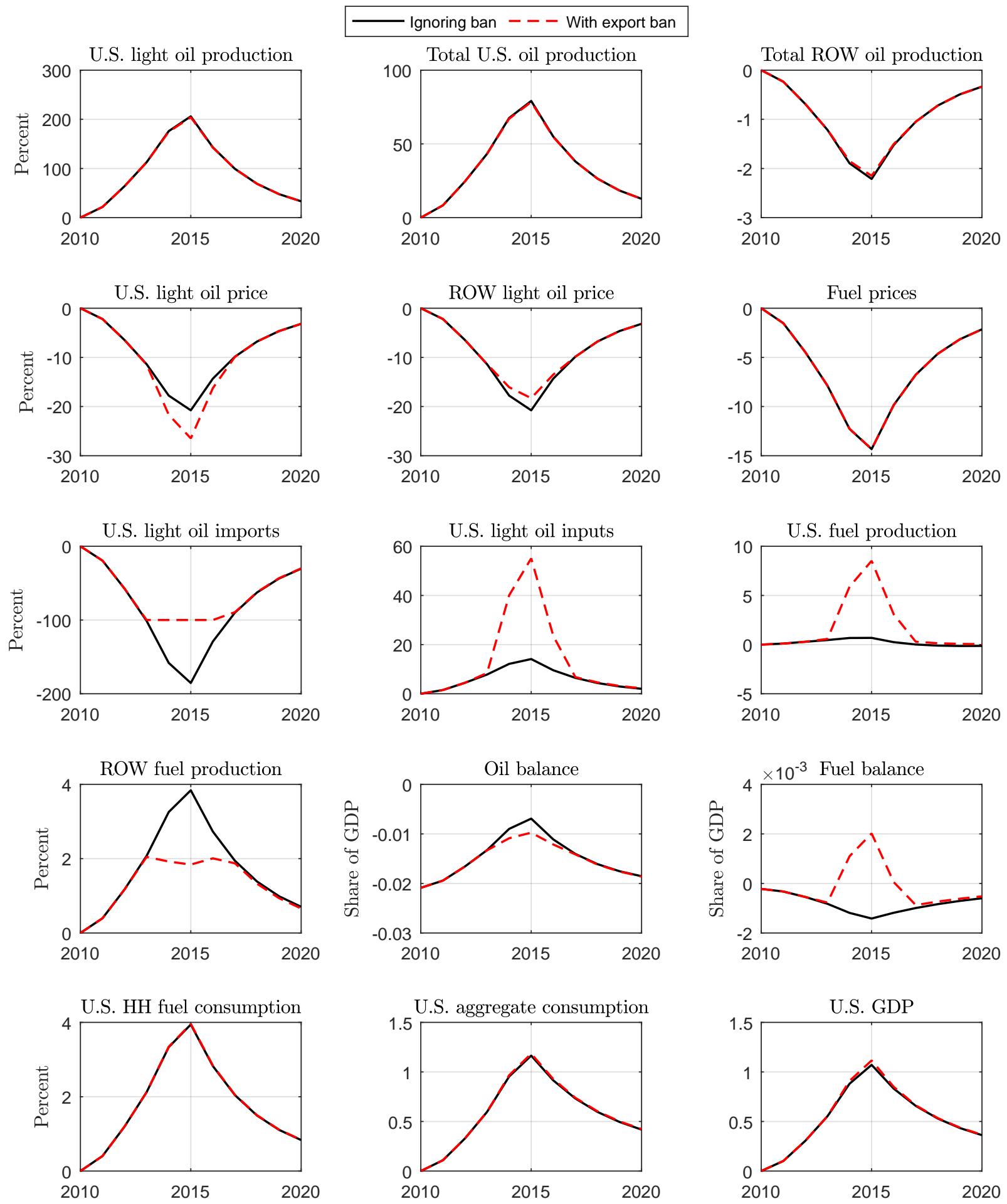

Note: Units are percent deviations from the steady state. 
Figure 6.2: Impulse responses to a light oil productivity shock, with and without export ban
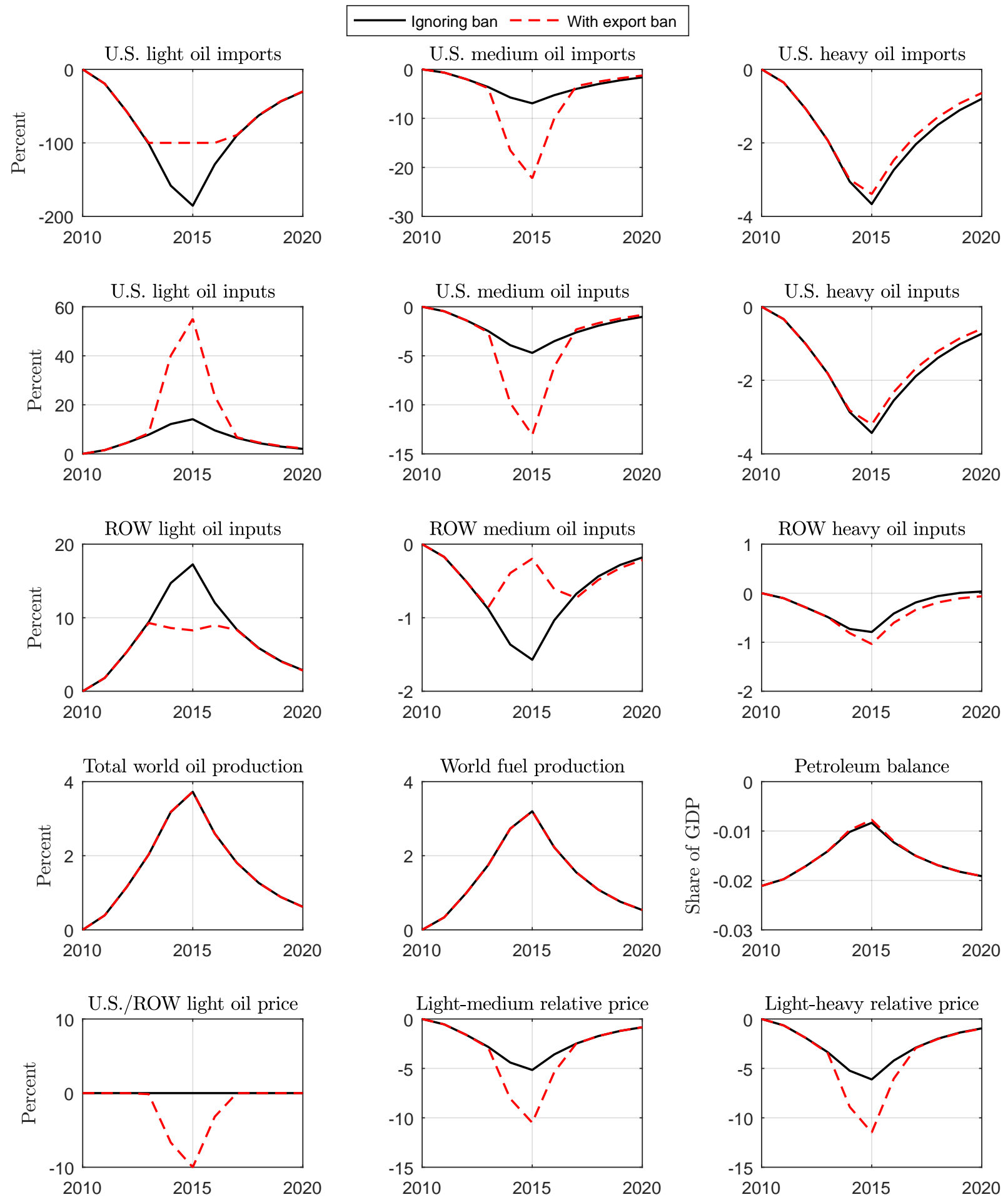

Note: Units are percent deviations from the steady state. 
Table 6.1: Percent changes from 2010 to 2015: Model vs. Data

\begin{tabular}{lcc} 
Variable & Data & Model \\
\hline \hline U.S. light oil production & 204 & 204 \\
U.S. light oil prices & -42 & -27 \\
U.S. - ROW light oil price differential & -4 & -10 \\
U.S. light oil imports (net) & -95 & -100 \\
U.S. light refiner inputs & 57 & 53 \\
\hline
\end{tabular}

Note: Annual data for real LLS and Brent oil prices are considered for the U.S. and the ROW light oil prices, respectively.

\subsection{Longer-term Increase in U.S. Light Oil Supply}

Our experiment presented in section 5 and subsection 6.1 matches U.S. light crude production up until 2015. After that, the path of production is assumed to decline at a pace determined by the persistence of the productivity shocks. However, forecasts as of late 2015 pointed to further increases in U.S. shale production in years to come. In this section, we investigate how incorporating a more persistent increase in U.S. light oil supply matching these forecasts affects our results.

To capture expectations of shale production beyond 2015, we use the EIA's forecast for light (tight) oil production from 2016 to 2020, found in their 2016 Annual Energy Outlook (AEO) report. This version of the AEO was put together at the end of 2015 and, therefore, presents forecasts that would have been made using information available before the ban was lifted. We derive a set of shocks that ensure U.S. light crude production grows at the pace seen in those forecasts.

Figure 6.3 shows the main set of results under this experiment. The EIA forecasts predicted continued but smaller increases in light oil production post-2015. As a result, the model predicts the export ban would have been a binding constraint through 2020, leading to a persistent gap between U.S. and foreign light oil prices. U.S. light oil prices are 10 percentage points lower than they would be without the ban. U.S. refiners significantly ramp up their use of light oil, and due to the persistent cost advantage, increase output 
more than 12 percent, at the expense of refiners elsewhere.

We find that the ban's macroeconomic implications are somewhat amplified under this scenario, although the difference is small. The oil balance as a share of GDP deteriorates by about 0.5 percentage points compared to the no ban scenario. The fuel balance, on the other hand, becomes positive by 2014 and improves significantly at more than 0.3 percent of GDP by 2020. The impact on U.S. household fuel consumption does not change much as the impact on fuel prices is negligible, although aggregate consumption rises slightly due to a slight increase in non-oil good consumption. A persistent increase in light oil production leads to nearly a 1.5 percent increase in U.S. GDP by 2020 and the export ban slightly amplifies that magnitude. 
Figure 6.3: Impulse responses when production follows the EIA forecasts through 2020
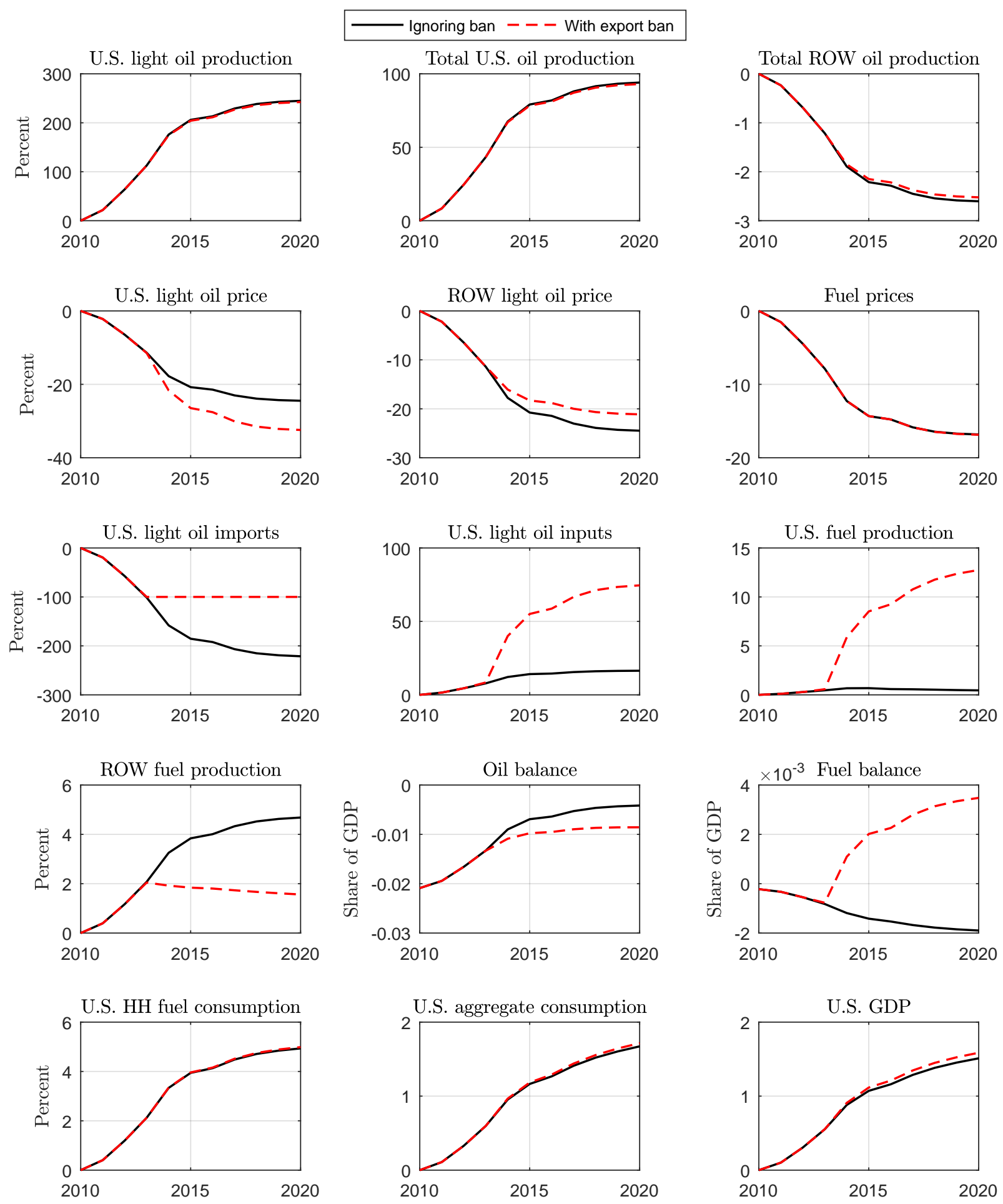

Note: Units are percent deviations from the steady state. 


\subsection{Was the ban binding in reality?}

According to our model, the export ban on crude oil was a binding constraint from 2013 to 2015. We now try to review evidence from the data to see whether the model prediction is consistent with the data. ${ }^{18}$

We approach this question in two ways. First, we consider several predictions from the model that can be checked in the data. We focus primarily on variables that are closely connected to the market for light crude oil. Second, we take advantage of the fact that the U.S. crude oil export ban had several loopholes. These loopholes could act as release valves for pressure that might arise in the market if the ban became a binding constraint.

We focus on three predictions of the model if the export ban was binding at some point in time. First, an unusually large spread should develop between light oil in the U.S. and outside the U.S. Second, the model predicts that imports of light oil should become zero. Finally, and related to the second, if the ban is a binding constraint, it could actually prevent exports of light crude oil.

First, we turn to the prediction that light crude oil in the U.S. should sell at a discount to light oil outside the U.S. if the ban binds. ${ }^{19}$ Using West Texas Intermediate crude prices may be problematic as the interior of the U.S. faced some logistical constraints that affected prices of WTI relative to other benchmarks. Given this, we instead use Louisiana Light Sweet (LLS) as our light oil price. This is a light crude oil similar in nature to WTI but is priced in the Gulf Coast of the U.S. We use Brent crude for our measures of foreign light oil prices.

Figure 6.4 plots the relative price of LLS to Brent. Starting in late 2013, we see that the relative price of LLS to Brent declined to unusually low levels compared to where it was in previous years. This continued through much of 2015. After the ban was removed, the relative price has generally remained close to levels seen in the years before 2013, and has

\footnotetext{
${ }^{18}$ Çakır Melek and Ojeda (2017) [18] analyzes oil market data for the same time period and provides evidence that the ban distorted oil flows and prices during the shale boom.

${ }^{19}$ We do not consider the predictions regarding the price of light relative to medium and heavy as there were changes in the supply of both those types of crude outside the U.S. that would have impacted their prices. Since we have not modeled those changes in supply, we focus on light crude oil.
} 
Figure 6.4: Relative price of Louisiana Light Sweet to Brent crude oil

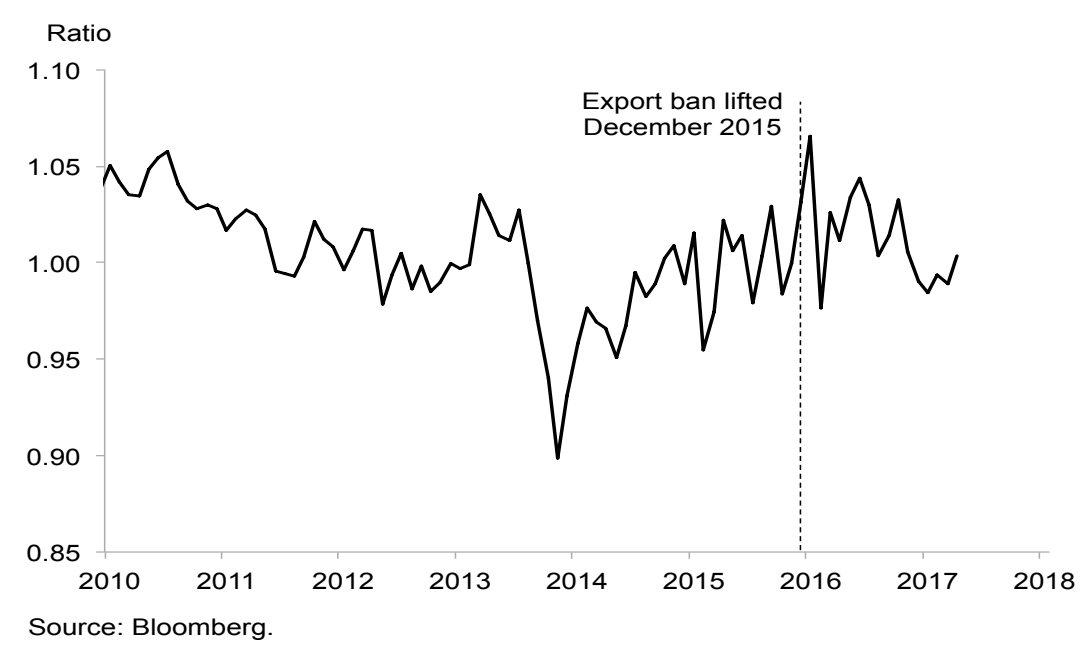

never fallen to the abnormal levels seen in late 2013 and early 2014.

A review of Table 2.2 suggests that the second prediction of the model does not appear to hold in the data. At no point in time did imports of "light" crude oil become zero. However, the EIA import data allows us to consider more disaggregated slices of the crude import data for light oil, which are shown in Figure 6.5. When we look at the import data for crude oil with API gravity higher than 40, we see that these imports did, indeed, fall to near zero for several years.

We point out here that our modeling decision to define "light" oil as API gravity 35 and above is driven by data limitations for the production data. It is known from other analysis that most U.S. shale oil actually has API of 40 and above. ${ }^{20}$ When viewed from this context, it seems natural that the first crude oils that would get crowded out are those of relatively high API gravity. And indeed, we see that imports of very light crude approach zero first, followed by those slightly below.

Finally, we are able to make firm statements about whether the ban constrained exports, because the ban was removed at the end of 2015 and we now have export data for 2016. We plot this data in Figure 2.3. The black line shows total crude exports, and it shows that U.S. crude exports increased in 2016 compared to 2015, despite the fact that U.S. crude production actually declined that year.

\footnotetext{
${ }^{20} \operatorname{EIA~(2015)[41].~}$
} 
Figure 6.5: U.S. imports of light crude oil by API gravity

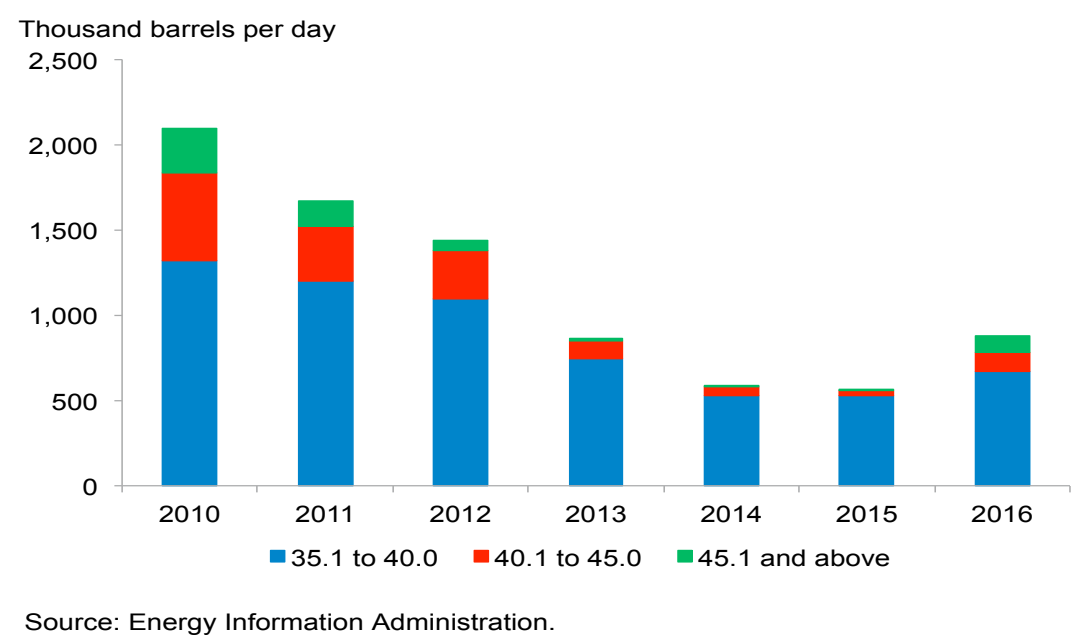

The export ban policy had a loophole in it that allowed for exports of crude oil to Canada, so long as the crude oil was to be processed in Canada and the fuels used for domestic consumption therein. In other words, if the desire to export crude oil was large enough, it was possible to try and use this loophole to export crude to Canada and indirectly back out Canadian imports of oil from another country. The dashed red line shows that exports of crude to Canada did indeed start increasing in 2013 through 2015. Since this loophole was not heavily used at any point before this time, this suggests that the ban had likely become binding.

Overall, we believe the evidence presented here is very suggestive that the crude oil export ban became a binding constraint sometime in 2013 and remained a constraint through 2015.

\section{Sensitivity analysis}

In our baseline calibration, we restricted the supply elasticity of different types of oil to be equal to each other across the two countries. In reality, though, the supply of shale oil appears to be more responsive to price changes than other types of oil production. Shale producers are smaller and more nimble than many conventional oil producers, and shale wells can come online significantly faster than many other types of oil wells. In order to investigate the implications this might have on the results, we consider an alternative calibration where 
we set the price-elasticity of supply for U.S. light oil production to 0.39 , three times its baseline value.

Figure 7.1 presents the results for this case. The set of variables in the figure are the same as those presented in Figure 6.1. To generate the responses, we fed in the same set of shocks that were used in the baseline model with the export ban. The solid lines are the responses from the baseline model, and the dashed lines are from the alternative calibration.

Overall, the higher light oil supply elasticity amplifies all of the responses. A higher elasticity of supply means lower production costs for light oil producers in the U.S., leading to higher output than the low supply elasticity case. This in turn brings a sharper decline in light oil imports, lower light oil prices, increased use of light oil inputs by U.S. refineries and more U.S. fuel production. The increase in light oil production improves the oil balance, and the higher fuel production leads to an improved fuel balance. Fuel prices decline about 2.5 percentage points more than the baseline, increasing fuel consumption and aggregate consumption by U.S. households. The increase in GDP is more than 1.1 percent by 2015 . In sum, the higher supply elasticity for light oil makes U.S. consumers better off.

We next consider the importance of the elasticity of substitution between different oil types in the refining sector. In the baseline calibration, the two elasticities are set equal across countries. However, the U.S. refining system is well known to be the most complex in the world. It also has a very large and diverse set of refiners, from those that specialize in just processing one type of oil to others that can choose to vary their crude inputs. So, it seems plausible that the U.S. refining complex is more able to substitute between different crude types than the rest of the world, particularly for light and medium crudes.

We consider this by setting the elasticity of substitution between light and medium oil, $\eta^{\text {oil }}$, to be different in the U.S. vs. ROW. Our baseline calibration is based on an elasticity of substitution value of 3.65. We increase the value for the U.S. elasticity by 50 percent, to 5.475 .

Figure 7.2 shows the main set of results for this exercise. Overall, we do not find many major changes in the results. The price of light oil declines less than the baseline model. This occurs as refiners in the U.S. are more easily able to substitute towards light oil from medium, which means a smaller price discount is required to get refiners to process the excess 
supply of light oil. We find that fuel production by U.S. refiners increases by less than the baseline calibration, leading to less crowding out of ROW production. We do not find any significant impacts on the broader economy. 
Figure 7.1: Impulse responses with higher U.S. light oil supply elasticity (.39 vs .13)
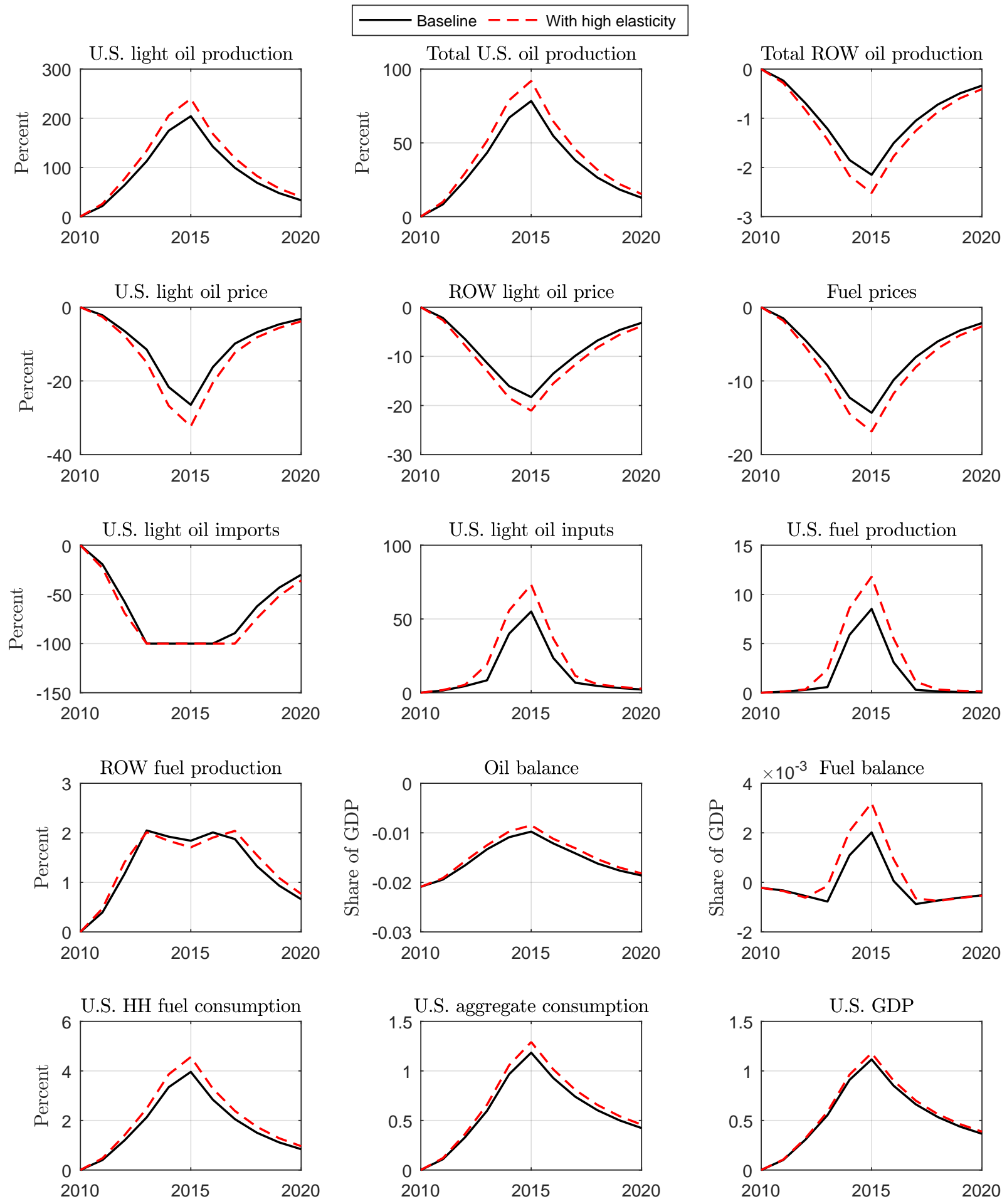

Note: Units are percent deviations from the steady state. 
Figure 7.2: Impulse responses with higher $\eta^{\text {oil }}$ in U.S. refining
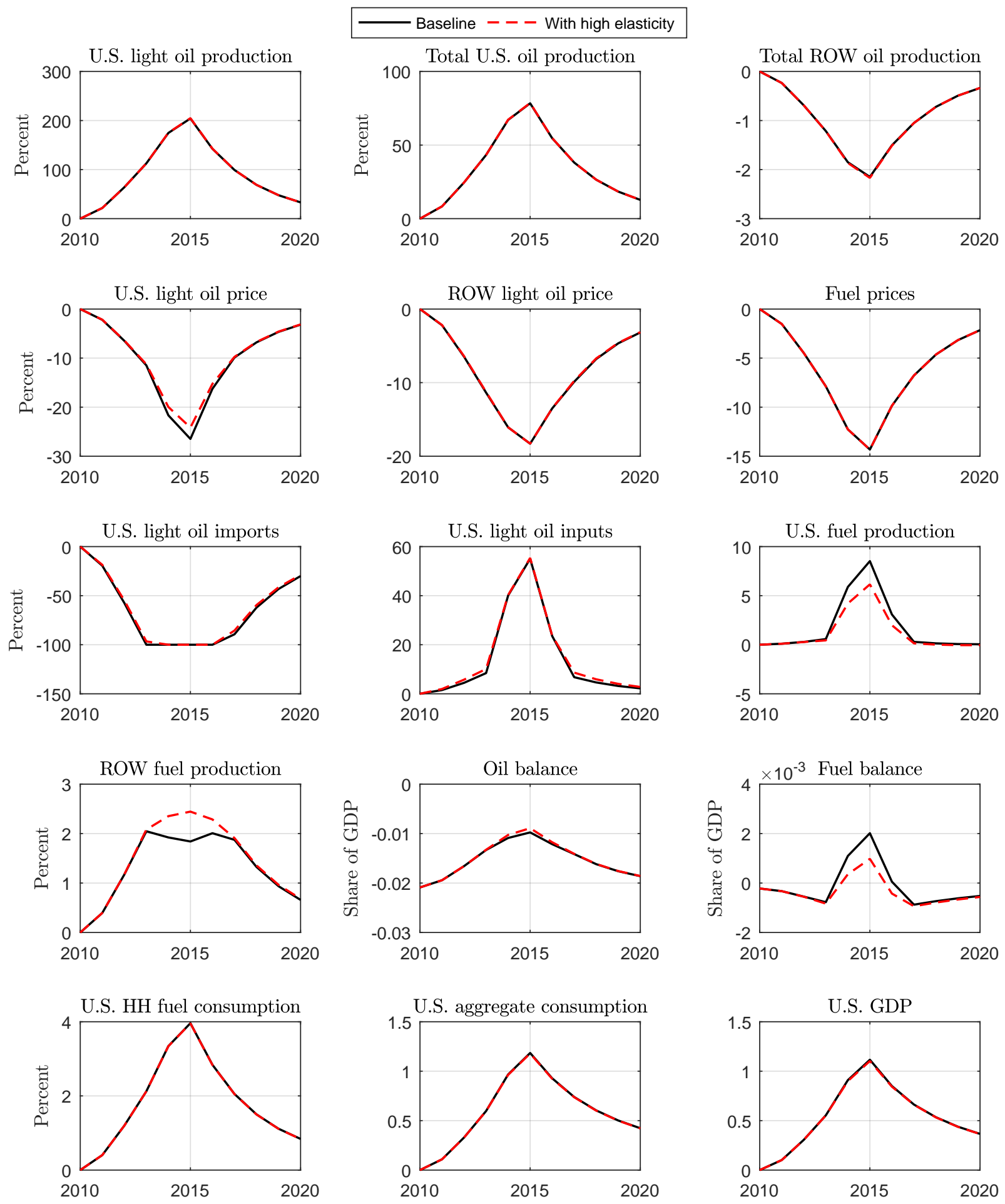

Note: Units are percent deviations from the steady state. 


\section{Conclusion}

In this paper we introduce a two-country DSGE model that incorporates a refining sector and different types of crude oil. The model is used to consider the effects of the shale oil boom and the U.S. crude oil export ban on both the oil and refining sectors, as well as the broader economy. The introduction of different types of crude oil, which are modeled as imperfect substitutes as inputs into the refining process, allows us to take into account the fact that oil produced from shale plays is primarily light crude oil and that refining sectors in the U.S. and the rest of the world specialize in processing different types of oil.

Under a free trade scenario, we find that a light oil boom of the same magnitude as the shale boom in the U.S. reduces light oil prices by 20 percent, increases U.S.' use of light crude at the expense of other types, and makes the U.S. a net exporter of light crude oil. It also lowers fuel prices by about 14 percent, and increases U.S. GDP by more than 1.0 percent, a significant impact.

Taking the export ban into account, our model predicts that the ban was binding in 2013 through 2015. The impact of the ban was primarily concentrated in the energy sector, especially the refining sector. Light oil prices were artificially low in the U.S. relative to the rest of the world, and refiners in the U.S. processed more light oil than they would have otherwise. The impact of the ban on GDP and fuel prices was negligible. Although we only relied on a single shock to generate changes, overall, the model has done a good job in explaining changes seen in the data. 


\section{References}

[1] Adjemian, Stephane, Houtan Bastani, Michel Juillard, Frederic Karame, Junior Maih, Ferhat Mihoubi, George Perendia, Johannes Pfeifer, Marco Ratto, and Sebastien Villemot. 2011. "Dynare: Reference manual, version 4." Dynare Working Paper Series 1.

[2] Arezki, Rabah, Valerie A. Ramey, and Liugang Sheng. 2017. "News shocks in open economies: Evidence from giant oil discoveries." The Quarterly Journal of Economics $132(1): 103-55$.

[3] Backus, David K., and Mario J. Crucini. 2000. "Oil prices and the terms of trade." Journal of International Economics 50: 185-213.

[4] Backus, David K., Patrick J. Kehoe, and Finn E. Kydland. 1992. "International real business cycles." Journal of Political Economy 100 (4): 745-75.

[5] Backus, David K., Patrick J. Kehoe, and Finn E. Kydland. 1994. "Dynamics of the trade balance and the terms of trade: The J-curve?" The American Economic Review $84(1): 84-103$.

[6] Balke, Nathan S., Michael D. Plante, and Mine K. Yucel. 2015. "Fuel subsidies, the oil market and the world economy." The Energy Journal 36(S): 99-127.

[7] Baumeister, Christiane, and James Hamilton. 2015. "Structural interpretation of vector autoregressions with incomplete identification: Revisiting the role of oil supply and demand shocks." Working Paper.

[8] Bausell Jr., Charles W., Frank W. Rusco, and W. D. Walls. 2001. "Lifting the Alaskan oil export ban: An intervention analysis." The Energy Journal 22 (4): 81-94.

[9] Baxter, Marianne, and Mario J. Crucini. 1995. "Business cycles and the asset structure of foreign trade." International Economic Review 36 (4): 821-54.

[10] Bjornland, Hilde C., Frode Nordvik, and Maximilian Rohrer. 2016. "How flexible is US shale oil production? Evidence from North Dakota." Working Paper. 
[11] Bodenstein, Martin, Christopher J. Erceg, and Luca Guerrieri. 2011. "Oil shocks and external adjustment." Journal of International Economics 83 (2). 168-84.

[12] Bordoff, Jason, and Trevor Houser. 2015. "Navigating the U.S. oil export debate." Columbia SIPA Center on Global Energy Policy, 2015-01.

[13] Bornstein, Gideon, Per Krusell, and Sergio Rebelo. 2017. "Lags, costs, and shocks: An equilibrium model of the oil industry." National Bureau of Economic Research (NBER) Working Paper 23423.

[14] Brown, Stephen P. A., Charles Mason, Alan Krupnick, and Jan Mares. 2014. "Crude behavior: How lifting the export ban reduces gasoline prices in the United States." Resources for the Future 2014-03.

[15] Brown, Phillip, Robert Pirog, Adam Vann, Ian F. Fergusson, Michael Ratner, and Jonathan L. Ramseur. 2014. "U.S. crude oil export policy: Background and considerations." Congressional Research Service 2014-03.

[16] Christiano, Lawrence J., Martin Eichenbaum, and Charles L. Evans. 2005. "Nominal rigidities and the dynamic effects of a shock to monetary policy." Journal of Political Economy 113 (1): 1-45.

[17] Crucini, Mario J., and James Kahn. 1996. "Tariffs and aggregate economic activity: Lessons from the Great Depression." Journal of Monetary Economics 38: 427-67.

[18] Çakır Melek, Nida, and Elena Ojeda. 2017. "Lifting the U.S. crude oil export ban: Prospects for increasing oil market efficiency." Federal Reserve Bank of Kansas City Economic Review 2017 (2).

[19] Ebinger, Charles K., and Heather L. Greenley. 2014. "Changing markets: Economic opportunities from lifting the U.S. ban on crude oil exports." Brookings Institution 2014-09.

[20] Eni. 2017. "Eni World Oil and Gas Review 2017."

[21] Exxon. 2016. "Exxon 2016 Energy Outlook." 
[22] Farrokhi, Farid. 2016. "Global Sourcing in Oil Markets." Purdue University Dissertation 2016-08.

[23] Grossman, Valerie, Adrienne Mack, and Enrique Martinez-Garcia. 2014. "A new database of global economic indicators." Journal of Economic and Social Measurement 39 (3): 163-97.

[24] Guerrieri, Luca, and Matteo Iacoviello. 2015. "Occbin: A toolkit to solve models with occasionally binding constraints easily." Journal of Monetary Economics 70 (3): 22-38.

[25] IHS. 2014. "U.S. crude oil export decision: Assessing the impact of the export ban and free trade on the economy."

[26] IHS. 2015. "Unleashing the supply chain: Assessing the economic impact of a U.S. crude oil free trade policy."

[27] Kang, Wensheng, Ronald A. Ratti, and Joaquin Vespignani. 2016. "The impact of oil price shocks on the U.S. stock market: A note on the roles of U.S. and non-U.S. oil production." Economics Letters 145: 176-81.

[28] Kilian, Lutz. 2016. "The impact of the shale oil revolution on U.S. oil and gasoline prices." Review of Environmental Economics and Policy 10 (2): 185-205.

[29] Kilian, Lutz. 2017. "How the tight oil boom has changed oil and gasoline markets." CEPR Discussion Paper DP-11876.

[30] Kumins, Larry. 2005. "West Coast and Alaska oil exports." Congressional Research Service 2005-05.

[31] Langer, Lissy, Daniel Huppmann, and Franziska Holz. 2016. "Lifting the US crude oil export ban: A numerical partial equilibrium analysis." Energy Policy 97: 258-66.

[32] Leduc, Sylvain, and Keith Sill. 2007. "Monetary policy, oil shocks, and TFP: Accounting for the decline in U.S. volatility." Review of Economic Dynamics 10 (4): 595-614.

[33] Manescu, Cristiana Belu, and Galo Nuno. 2015. "Quantitative effects of the shale oil revolution." Energy Policy 86 (2015): 855-66. 
[34] Medlock, Kenneth B. 2015. "To lift or not to lift? The U.S. crude oil export ban: Implications for price and energy security." Rice Universitys Baker Institute for Public Policy, Center for Energy Studies 2015-03.

[35] Mohaddes, Kamiar, and M. Hashem Pesaran. 2017. "Oil prices and the global economy: Is it different this time around?" Energy Economics 65 (6): 315-25.

[36] Mohaddes, Kamiar, and Mehdi Raissi. 2016. "The U.S. oil supply revolution and the global economy." Globalization and Monetary Policy Institute Working Paper 263.

[37] Nakov, Anton, and Galo Nuno. 2013. "Saudi Arabia and the oil market." Economic Journal, Royal Economic Society 123 (12): 1333-62.

[38] Plante, Michael D. 2014. "How should monetary policy respond to changes in the relative price of oil? Considering supply and demand shocks." Journal of Economic Dynamics and Control 44(C): 1-19.

[39] Timmer, Marcel P., Erik Dietzenbacher, Bart Los, Robert Stehrer, and Gaaitzen J. de Vries. 2015. "An illustrated user guide to the World Input-Output Database: The case of global automotive production." Review of International Economics 23: 575-605.

[40] U.S. Energy Information Administration. 2014. "What drives U.S. gasoline prices?"

[41] U.S. Energy Information Administration. 2015. "U.S. crude oil production to 2025: Updated projection of crude types."

[42] Van Vactor, Samuel A.. 1995. "Time to end the Alaskan oil export ban." Policy Analysis, Cato Insitutute 227.

[43] Vidas, Harry, Martin Tallett, Tom OConnor, David Freyman, William Pepper, Briana Adams, Thu Nguyen, Robert Hugman, and Alanna Bock. 2014. "The impacts of U.S. crude oil exports on domestic crude oil production, GDP, employment, trade and consumer costs." ICF International and EnSys Energy submission to the American Petroleum Institute 2014-03. 
[44] Walls, W. D., and Xiaoli Zheng. 2016. "Shale oil boom and the profitability of US petroleum refiners." OPEC Energy Review 40: 337-53. 


\section{APPENDIX}

\section{A Data Sources}

The following series are available from Bloomberg:

Brent crude price: Bloomberg European Dated Brent Forties Oseberg Ekofisk (BFOE) price. (Bloomberg ID: EUCRBRDT).

Dubai crude price: Bloomberg Arabian Gulf Dubai Fateh crude oil spot price. (Bloomberg ID: PGCRDUBA).

Louisiana Light Sweet crude price: Bloomberg light Louisiana sweet crude oil spot price. (Bloomberg ID: USCRLLSS).

Mars crude price: Bloomberg Deepwater Sour Mars Blend crude oil spot price. (Bloomberg ID: USCRMARS).

Maya crude price: Bloomberg Latin America Maya crude oil spot price to U.S. (Bloomberg ID: LACRMAUS).

The following series are available from the U.S. Energy Information Administration:

U.S. crude oil exports: Annual data in thousands of barrels per day. Total exports and exports to Canada.

U.S. crude oil imports by API gravity: Annual data in millions of barrels per day. Data is broken into seven bins: API gravity 20 or less, 20.1 to 25.0, 25.1 to 30, 30.1 to 35.0, 35.1 to $40.0,40.1$ to 45.0 , and 45.1 and above. We define heavy imports as those of API gravity 25.0 and below, medium as 25.1 to 35.0, and light as 35.1 and above.

U.S. crude oil input to refiners: Annual data in millions of barrels per day. EIA series name is U.S. refinery and blender net input of crude oil.

U.S. refinery processing gains: Annual data in millions of barrels per day.

U.S. refinery production: Sum of U.S. crude oil input to refineries, refinery processing gain and petroleum products adjustment series found in Table 4a of the Short-term Energy Outlook.

U.S. total spending on fuel: Annual, nominal series in billions of dollars. This series is calculated as total spending on petroleum excluding LPG. Series is from Table ET1 of the 
State Energy Data 2015: Prices and Expenditures report.

Cost-share of crude oil in fuel production: Monthly data from the Gasoline and Diesel Fuel Update report. We take a simple average of the cost-share for gasoline and diesel (excluding taxes).

U.S. consumption of refined products: Annual series in millions of barrels per day. Calculated as total consumption excluding hydrocarbon gas liquids, ethanol and biodiesel. Consumption of biodiesel estimated as the difference between renewables and oxygenate production and fuel ethanol production. All series from Table 4a of the Short-term Energy Outlook.

Net imports of refined products: Annual series in millions of barrels per day. Calculated as total consumption of refined products minus U.S. refinery production.

The following series are from the Bureau of Economic Analysis:

U.S. real GDP: Quarterly data in chained, 2009 dollars.

U.S. nominal GDP: Annual, billions of dollars.

U.S. household spending on fuel: Annual, nominal series in billions of dollars. Sum of Personal Consumption Expenditures on "gasoline motor vehicle fuels, lubricants and fluids" and "fuel oil and other fuels."

U.S. oil trade balance: Constructed using annual series on imports and exports of crude oil, in millions of dollars.

U.S. fuel trade balance: Constructed using annual series on imports and exports of "fuel oil" and "other petroleum products," in millions of dollars.

Data available from other sources:

Rest-of-world real GDP: Quarterly series based on 39 countries. Individual data is aggregated with U.S. trade weights. Source: Database of Global Economic Indicators, Federal Reserve Bank of Dallas.

U.S. crude oil production by API gravity: Annual series in thousands of barrels per day. Data is available for ultra light and light crude oil, three types of medium crude and heavy crude. Source: World Oil and Gas Review 2017, Eni.

World crude oil production by API gravity: Annual series in thousands of barrels per day. Data is available for light, medium and heavy crude production. Source: World Oil 
and Gas Review 2017, Eni.

U.S. firm spending on fuel: Annual, nominal series in billions of dollars. Calculated as total spending on fuel minus household spending. Source: Authors' calculations.

Refining capacity by country: Annual series for crude distillation capacity (atmospheric), in barrels per day. Data source: 2010 Worldwide Refining Survey, Oil\&Gas Journal.

World refinery processing gains: Annual data in millions of barrels per day. Data source: International Energy Agency.

Labor compensation and value-added: Annual, nominal series for the petroleum and coal sector, and the total economy. Available for 40 countries, including the U.S. Source: World Input Output Database.

U.S. share of world GDP: Annual series. U.S. share of PPP-adjusted world GDP. Data source: International Monetary Fund.

U.S. and world population: Annual series, total population. Data source: United Nations.

Rest-of-world fuel use: Data is for 2010 and comes from the Energy Information Administration's International Energy Outlook 2014 and Exxon's 2016 Energy Outlook.

\section{B Modeling the export ban}

We address the U.S. oil export ban in the model as follows. We assume that crude oil is distributed by perfectly competitive firms, called distributors of crude oil. A distributor's problem is a tool for us to model an export ban on crude oil, which will be introduced into the distributor's problem as an inequality constraint. Moreover, we assume that there are iceberg trade costs for shipping crude oil. Adding trade costs allows the model to generate a small, positive spread between crude oil prices in the U.S. and the ROW. This is a feature of the data due to the costs of importing the marginal barrel of oil into the U.S. To match this feature of the data we work with a simple form of iceberg trade costs. If country 1 imports $o_{1, t}^{m}$ units of crude oil, then $\tau_{o 2} O_{1, t}^{m}$ units will be lost in transit, where $\tau_{o 2}>0$ is the iceberg cost of moving crude oil from country 2 to country 1 . We assume there is no cost of moving crude oil within country 1 or country 2. This form of trade costs implies that crude 
oil imports are given by $o_{1, t}^{m}=\frac{o_{1, t}^{f}-y_{1, t}^{o}}{1-\tau_{o 2}}$.

\section{B.1 Distributors of crude oil}

A perfectly competitive distributor purchases crude oil in domestic spot market or imports it, and then re-sells it to refined products producers (refineries) costlessly. In country 1, crude oil of type $k$ can be purchased in the domestic spot market at price $p_{11, t}^{o k}$ or imported from country 2 at $p_{2, t}^{o k}$. The oil distributor chooses output and imports of type $k$ crude oil to maximize the present discounted value of cash flow

$$
E_{0} \sum_{t=0}^{\infty} \beta^{t} \lambda_{1, t}\left\{p_{1, t}^{o k} o_{1, t}^{f k}-p_{11, t}^{o k} y_{1, t}^{o k}-p_{2}^{o k} o_{1, t}^{m k}\right\}
$$

subject to

$$
\begin{gathered}
o_{1, t}^{f k}=y_{1, t}^{o k}+\left(1-\tau_{o 2}\right) o_{1, t}^{m k} \\
o_{1, t}^{m k} \geq 0
\end{gathered}
$$

where $o_{1, t}^{m k}$ is the import of type $k$ crude oil, $o_{1, t}^{f k}$ is type $k$ crude oil demand by the refineries, and $\tau_{o 2}$ is the parameter determining the cost of importing crude oil from country $2 .^{21}$

So, the crude oil export ban in country 1 (U.S.) is modeled as an inequality constraint that prevents (net) imports of all types of crude oil, $k=l, m, h$, in country 1 from becoming negative, i.e. crude oil exports are impossible. For instance, consider the case of light oil, then the constraint would translate into $\frac{o_{1, t}^{f l}-y_{1, t}^{o l}}{\left(1-\tau_{o 2}\right)} \geq 0$. As both refiner use of light oil and production of light oil are chosen by the distributor, the constraint is endogenous. Therefore, the ability of refiners to substitute away from other types of oils towards light oil has implications for how strongly the constraint will bind and what kind of price differentials it is likely to generate.

Let $\psi_{t}^{k}$ be the multiplier on the inequality constraint for tyke $k$ crude oil. The first order conditions for the distributor's optimization problem are then given by

$$
p_{1, t}^{o k}=p_{11, t}^{o k}
$$

\footnotetext{
${ }^{21}$ Note that $\lambda_{i, t}$ is the lagrange multiplier on the household's budget constraint in country $i$.
} 
implying the spot price and the retail price of type $k$ crude oil are the same, and

$$
p_{2, t}^{o k}=\left(1-\tau_{o 2}\right) p_{1, t}^{o k}+\frac{\psi_{t}^{k}}{\lambda_{1, t}},
$$

and

$$
\psi_{t}^{k} o_{1, t}^{m k}=0
$$

In the case where the ban does not bind, $\psi_{t}^{k}$ equals zero and the price of type $k$ oil in the U.S., $p_{1, t}^{o k}$, will be equal to the cost of importing the marginal barrel of type $k$ oil from country 2. Due to shipping costs, there is a small, positive gap between type $k$ crude prices in the U.S. and ROW. Moreover, the type $k$ oil market clearing condition in this case will be given by

$$
y_{1, t}^{o k}+y_{2, t}^{o k}-\tau_{o 2} o_{1, t}^{m k}=o_{1, t}^{f k}+o_{2, t}^{f k} .
$$

However, when the ban binds, a gap is introduced between domestic and foreign type $k$ crude prices, and type $k$ crude oil market becomes segmented from the rest of the world, implying that $o_{1, t}^{f k}=y_{1, t}^{o k}$ and $o_{2, t}^{f k}=y_{2, t}^{o k}$.

The distributor's problem in country 2 is simply to choose output of type $k$ crude oil to maximize

$$
E_{0} \sum_{t=0}^{\infty} \beta^{t} \lambda_{2, t}\left\{p_{2, t}^{o k} o_{2, t}^{f k}-p_{22, t}^{o k}\left(y_{2, t}^{o k}-o_{1, t}^{m k}\right)\right\}
$$

subject to

$$
o_{2, t}^{f k}=y_{2, t}^{o k}-o_{1, t}^{m k}
$$

The first order condition for the distributor's optimization problem is given by

$$
p_{2, t}^{o k}=p_{22, t}^{o k} .
$$

In our simulations of the model with the export ban, we assumed $\tau_{o 2}=0$. 


\section{B.2 Solution method}

It is useful to briefly map our model conditions into the notation used in Guerrieri and Iacoviello (2015) [24]. In our model, country 1's crude oil exports are subject to an occasionally binding constraint, $o_{1, t}^{m k} \geq 0$ for $k=l, m, h$. The complementary slackness condition implies that $\psi_{t}^{k}=0$ when the constraint is slack. When the constraint binds, $o_{1, t}^{m k}=0$. The conditions in the reference regime, $M 1$, encompass $\psi_{t}^{k}=0$, and the function $g$ captures

$o_{1, t}^{m k} \geq 0$. The conditions in alternative regime, $M 2$, encompass the case when $o_{1, t}^{m k}=0$ and the function $h$ captures $\psi_{t}^{k}>0$. 